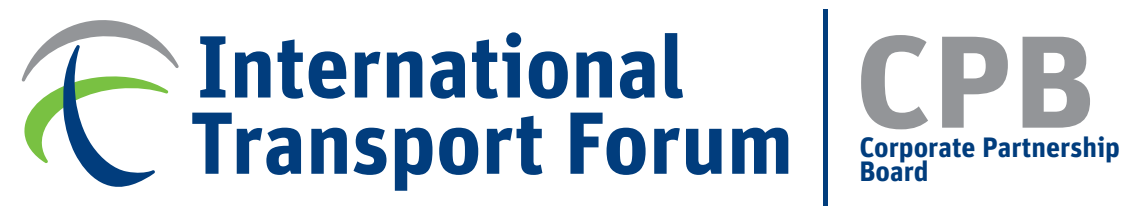

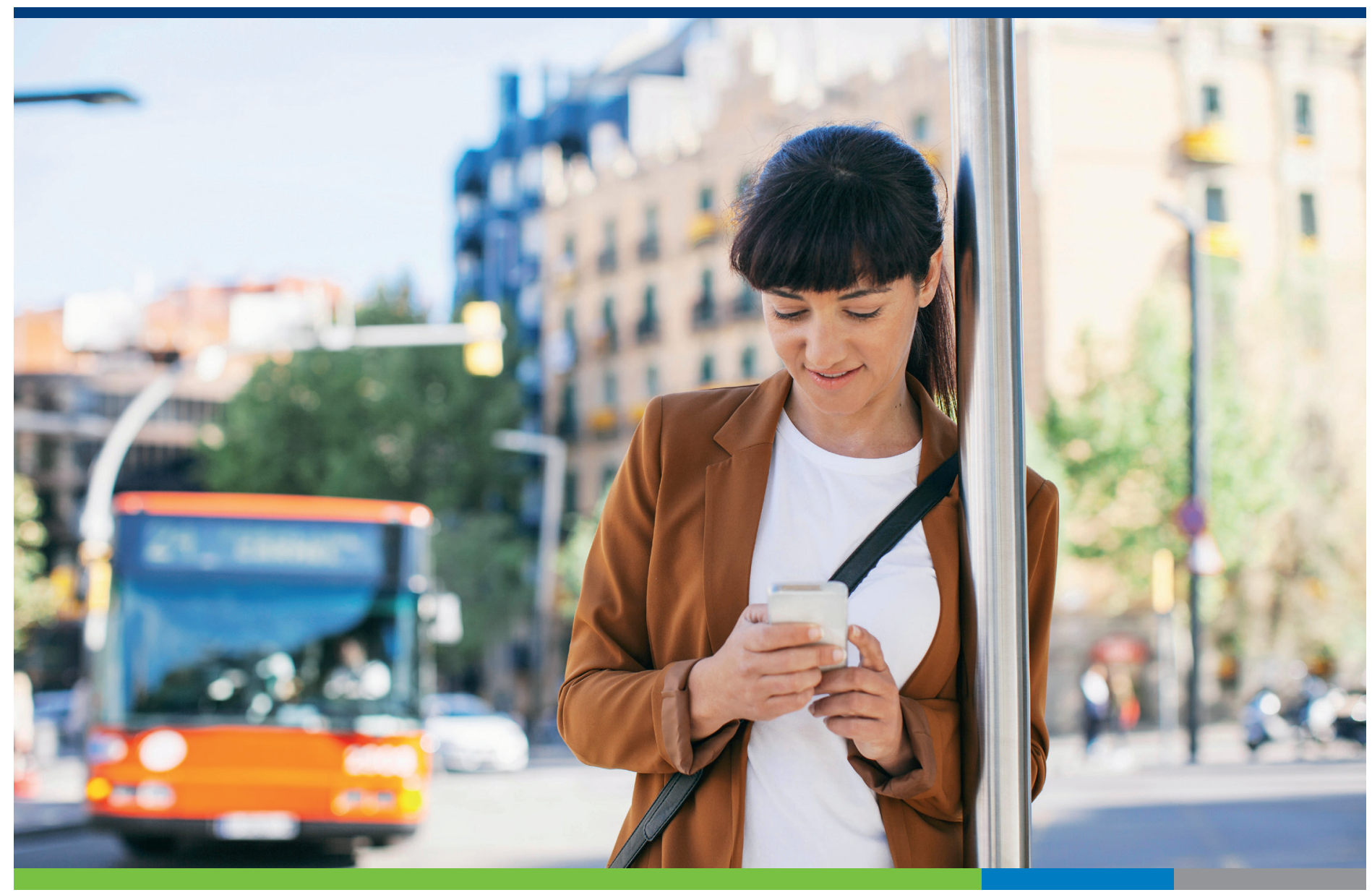

Shaping the Relationship Between Public Transport and Innovative Mobility

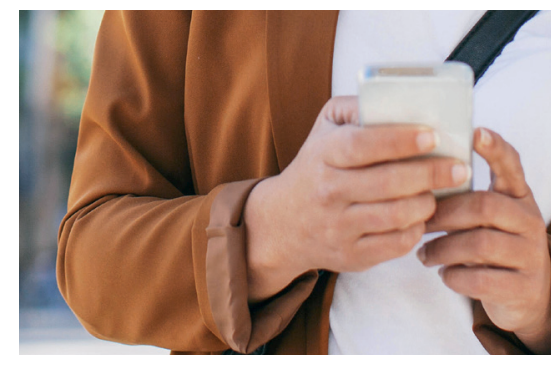

Corporate Partnership Board Report 


\section{Shaping the Relationship Between Public Transport and Innovative Mobility}

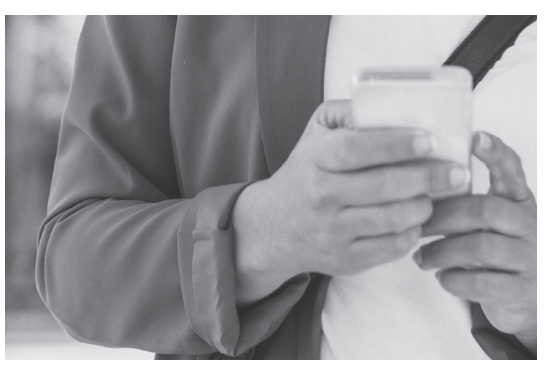

Corporate Partnership Board Report 


\section{About the International Transport Forum}

The International Transport Forum at the OECD is an intergovernmental organisation with 57 member countries. It acts as a think tank for transport policy and organises the Annual Summit of transport ministers. ITF is the only global body that covers all transport modes. It is administratively integrated with the OECD, yet politically autonomous.

ITF works for transport policies that improve peoples' lives. Our mission is to foster a deeper understanding of the role of transport in economic growth, environmental sustainability and social inclusion and to raise the public profile of transport policy.

ITF organises global dialogue for better transport. We act as a platform for discussion and pre-negotiation of policy issues across all transport modes. We analyse trends, share knowledge and promote exchange among transport decision makers and civil society. ITF's Annual Summit is the world's largest gathering of transport ministers and the leading global platform for dialogue on transport policy.

Our member countries are: Albania, Argentina, Armenia, Australia, Austria, Azerbaijan, Belarus, Belgium, Bosnia and Herzegovina, Bulgaria, Canada, Chile, China (People's Republic of), Croatia, Czech Republic, Denmark, Estonia, Finland, France, Former Yugoslav Republic of Macedonia, Georgia, Germany, Greece, Hungary, Iceland, India, Ireland, Israel, Italy, Japan, Korea, Latvia, Liechtenstein, Lithuania, Luxembourg, Malta, Mexico, Republic of Moldova, Montenegro, Morocco, Netherlands, New Zealand, Norway, Poland, Portugal, Romania, Russian Federation, Serbia, Slovak Republic, Slovenia, Spain, Sweden, Switzerland, Turkey, Ukraine, United Kingdom and United States.

\section{Disclaimer}

Funding for this work has been provided by the ITF Corporate Partnership Board. This report is published under the responsibility of the Secretary-General of the ITF. It has not been subject to the scrutiny of ITF or OECD member countries, and does not necessarily reflect their official views or those of the members of the Corporate Partnership Board. 


\section{Foreword}

The work for this report was carried out in the context of a project initiated and funded by the International Transport Forum's Corporate Partnership Board (CPB). CPB projects are designed to enrich policy discussion with a business perspective. They are launched in areas where CPB member companies identify an emerging issue in transport policy or an innovation challenge to the transport system. Led by the ITF, work is carried out in a collaborative fashion in working groups consisting of CPB member companies, external experts and ITF staff.

Many thanks to the members of the Corporate Partnership Board companies involved in this work: Ford, Google, PTV Group, Transdev, Uber.

The report draws conclusions from a workshop held in San Francisco on 21 November 2016. Many thanks to The City Innovate Foundation and Superpublic for hosting the workshop at their headquarters in City Innovate Foundation. Special thanks to Kamran Saddique, Founder \& Executive Director of Superpublic; Gert Christen, Chief Operating Officer, Superpublic; and Garrett Brinker, Policy Innovation Lead, Superpublic for their invaluable assistance.

Participants of the workshop included:

Jameson Auten, Kansas City, Missouri Area - Chief, Regional Service Delivery and Innovation Division Kansas City Area Transportation Authority, USA

Zak Accuardi, Program lead, New Mobility, Transit Center, New York, USA

Garrett Brinker, Policy Innovation Lead, City Innovate Foundation, San Francisco, USA

Andrea Broaddus, Future Mobility Research, Bosch, USA

Emily Castor, Director, Public Policy, Lyft, USA

Gert Christen, Chief Operating Officer, City Innovate Foundation, San Francisco, USA

Carlos Cruz-Casas, Assistant Director, Department of Transportation and Public Works, Miami-Dade County, USA

Mariko Davidson, Civic Innovation \& Partnerships Strategist, Microsoft, USA

Colin Hughes, Director of National Policy \& Project Evaluation, Institute for Transport and Development Policy, USA

Michael Hurwitz, Director of Transport Innovation, Transport for London, UK

Scott Mauvais, Director, Technology \& Civic Innovation, Microsoft, USA

Jon McBride, Operations Director, Bridj, USA

Jerome Pourbaix, International Public Transport Association (UITP), France

Maria Rautavirta, Deputy Director of Data Unit, Finnish Ministry of Transport and Communications, Finland

Seleta Reynolds, General Manager, Los Angeles Department of Transport, USA

Bruce Schaller, Schaller Consulting, USA

Susan Shaheen, Director, Innovative Mobility Research, Transportation Sustainability Research Center, Berkeley, USA

Paige Tsai, Transportation Policy and Research, Uber, USA

Michael Uribe, Regional Vice President, Zipcar, USA

Qianyan Xie, Smart Mobility - Asia Pacific Lead, Ford Motor Company, USA

The principal author of this report was Philippe Crist of the International Transport Forum. Special thanks to Ann Frye for her insightful and valuable input and comments, particularly on the aspects concerning mobility for the ageing. Many thanks to Liv Gudmundson for copy-editing.

The project was co-ordinated by Philippe Crist and Sharon Masterson of the International Transport Forum. 


\section{Table of contents}

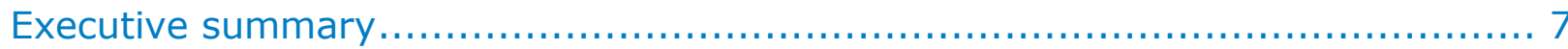

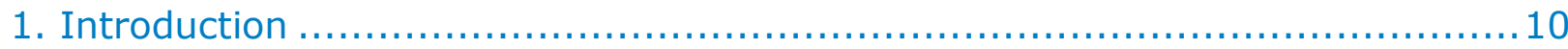

2. Getting around cities: Then, now and in the future $\ldots \ldots \ldots \ldots \ldots \ldots \ldots \ldots \ldots \ldots \ldots \ldots 12$

Traditional urban transport modes: Limited choices, broad uptake .............................. 12

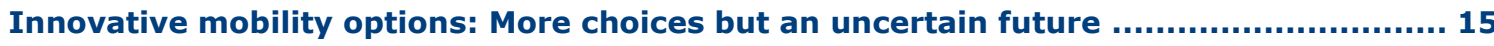

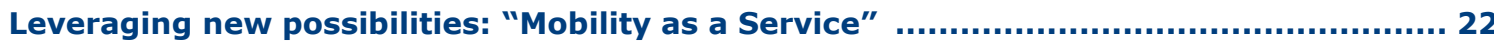

3. Shifting the status quo: Where mobility services and public transport are

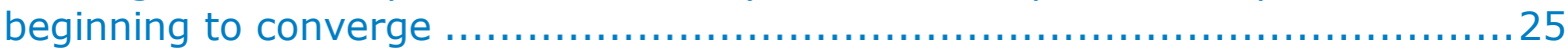

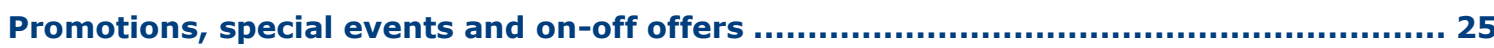

Formal partnerships with public transport involving subsidies and integration ............. 27

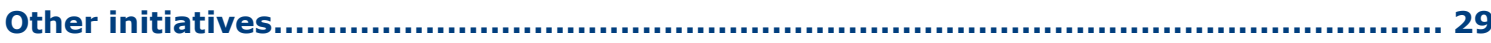

Features of current ride service: Public transport partnerships ............................. 30

4. Framing the convergence of ride services and public transport....................33

From public transport to a "Mobility as a Service" ecosystem ..................................... 33

Comparing mobility services and public transport........................................................ 34

Managing competition between innovative mobility services and traditional public transport ...................................................................................................................... 36

Adopting structures aligned with the range of mobility services on offer ...................... 39

Current public transport service procurement practices and ride services ....................41

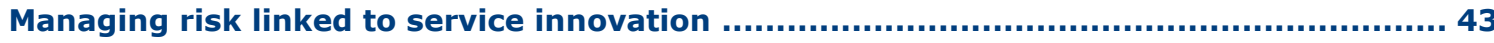

Leveraging government assets to guide convergence ........................................... 44

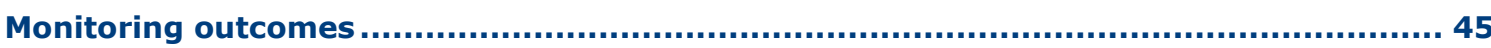

5. Ensuring equitable access for an ageing population $\ldots \ldots \ldots \ldots \ldots \ldots \ldots \ldots \ldots \ldots \ldots . \ldots . \ldots . \ldots$

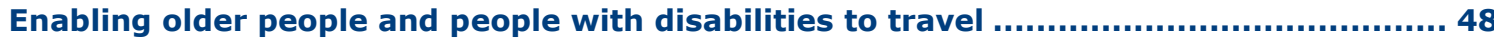

Current accessibility trends in transport ....................................................................... 49

Suggested prerequisites for inclusive mobility services............................................ 51

Can mobility services meet everyone's needs? ....................................................... 52

What about the future? Testing equitable accessibility of shared mobility services ....... 52

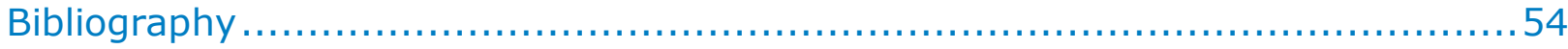

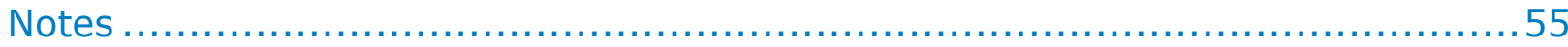




\section{Tables}

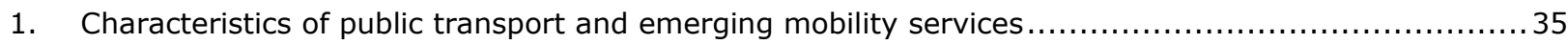

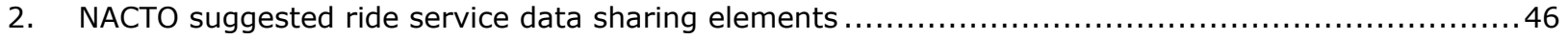

\section{Figures}

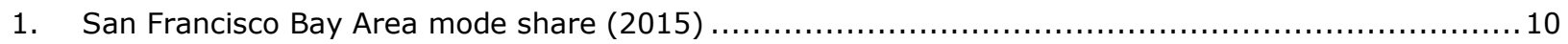

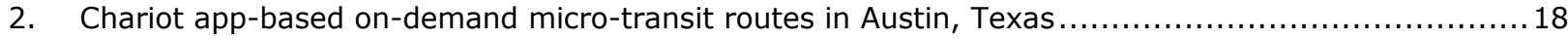

3. Additional travel generated by Transportation Network Companies in New York City (2016) ............21

4. Uber pick-ups and drop-offs (blue) within a quarter mile of suburban rail services (black)

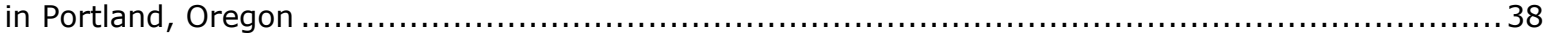

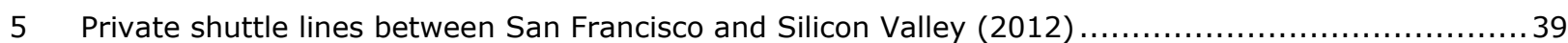

6. Public service contract components for public transport services and ride services (indicative).........42 


\section{Executive summary}

\section{What we did}

This report investigates the convergence of public transport and innovative mobility solutions, such as ride services, car- and bicycle-sharing, app-enabled on-demand micro-bus services, and platforms that connect app-using travellers and drivers. It examines the role of public authorities in ensuring this convergence supports commercial innovation as well as public policy objectives and identifies principles to guide partnerships between innovative mobility services and public transport operators. The report also explores where action may be needed to ensure that this convergence does not lead to reduced mobility options for those that have difficulty using existing transport modes, and in particular, how the needs of an ageing population may be met in an evolving mobility service landscape.

This study was organised under the auspices of the International Transport Forum's Corporate Partnership Board (CPB). It is based on a workshop with commercial actors, public authorities and other experts that took place in November 2016, and interviews with various officials and experts as well as input from CPB member companies. Additionally, extensive desk research for this study was carried out by the International Transport Forum.

\section{What we found}

The rapid deployment of new types of mobility services has the potential to change the way in which urban mobility and access are delivered. This will have an impact on the nature of public transport. The convergence of public transport and ride services in particular provides an opportunity to deliver better mobility outcomes for a broader share of the population. At the same time it poses clear risks to the provision of equitable and sustainable mobility for all.

Ride services like those offered by Didi Chuxing, Grab, Lyft, Ola, Uber and other innovative mobility options - including app-based microtransit platforms like Chariot and car- and bicycle-sharing - account for a small share of trips in most urban areas. Nonetheless, they are starting to have an impact of trip-making behaviour where they are present and are starting to be seen as a potential complement for first and last mile connections. In low density regions difficult to service with public transport and areas where public transport is available but quality is perceived to be lacking, ride services may also come to be seen as an alternative.

Some public transport operators and authorities are already exploring partnerships with app-enabled mobility services. Most of these initiatives are taking place in the United States - partly because of the popularity of ride services there, partly because many urban areas there have difficulty providing attractive public transport. Many of the partnerships described in this report are pilot projects or promotional campaigns and at present there is no evidence for a permanent shift in public transport service delivery towards structural partnerships with ride services. Nonetheless, authorities and ride-service operators are using these pilots to test new ways of improving mobility outcomes where it is difficult to provide quality public transport.

Co-operation with ride services is unlikely to save poor-quality public transport, however. Providing first and last mile connections via ride services to poor quality (i.e. unreliable, crowded, slow, infrequent) public transport will not suffice to attract users to public transport; it certainly seems unlikely to entice car users to switch. Such co-operations may result in cost savings for public transport operators in certain contexts. But introducing ride services alone will not reverse a decline in ridership if the overall service offer does not result in improved outcomes for travellers. 


\section{What we recommend}

\section{Focus on improving overall mobility outcomes, not just on lowering public transport costs}

Replacing more expensive, less demand-responsive and less flexible public transport with less expensive, more demand-responsive and more flexible ride services (or other combinations of innovative mobility services) can free funds that public transport operators could allocate to improving service quality. Cost savings should not be the only motivation for seeking synergies between ride services and public transport. These synergies can be leveraged to provide improved outcomes for travellers while at the same time allowing public authorities to deliver on important public policy objectives such as improved equity, reduced congestion and improved environmental outcomes.

\section{Set a vision for urban transport that includes full integration of innovative mobility options}

Public policy is best served when it is framed within a coherent set of visions and goals. These should be incorporated into a publicly vetted plan that sets out how authorities intend to deliver on these goals despite fast-changing circumstances. This is the case with the public policy approach to innovative mobility services, automated driving and generally how digitally-driven changes may fundamentally challenge the concept of public transport. One good example of this type of plan is the city of Los Angeles' "Urban Mobility Plan in a Digital Age" that re-orients the focus to Mobility as a Service.

Ensure partnerships between public transport and innovative mobility operators to improve mobility for all people, including those with disabilities

If innovative mobility services complement or replace accessible mainstream public transport, they will need to provide at least the same degree of spontaneity and flexibility to travel when the individual wants or needs. Where frequent accessible buses and on-street hail taxis are available, licensed ride services must not erode overall levels of accessible transport. App-based ride services can improve overall accessibility by better matching supply of accessible vehicles and demand - but only if the design of the service and of the partnership takes into account the specific needs of travellers with impairments.

Target low-performing or costly routes, and leverage government assets to guide convergence

Where public transport is expensive and service quality is low, replacing certain poorly-performing, expensive bus services may increase the overall attractiveness of public transport. By undertaking inventories of existing public transport routes to examine the potential for alternative service delivery models, public authorities and public transport operators can evaluate where synergies with innovative mobility services are strongest. Governments can also leverage assets they control to guide this convergence: Re-allocating parking space at public transport hubs, for instance, can improve the convenience of trips by public transport combined with rides-services; as can the creation of curb-side pick-up and drop-off zones.

\section{Split regulatory oversight from operation of urban transport and adapt procurement practices}

The governance of public transport will play an essential role in either facilitating or impeding the convergence of traditional and innovative mobility services, and of ride services in particular. Split responsibilities complicate the task of aligning outcomes. For instance the regulation of ride services may be in the hands of an authority in charge of taxi or for-hire services, while public transport regulation may fall under a completely different authority. Governance models that unify regulatory oversight and planning functions, define quality outcomes and performance objectives, and set contractual relationships to deliver these across a wide range of mobility operators may accelerate the integration of these into a co-ordinated ecosystem. Procurement rules for ride services and platform-based micro-transit services, however, will 
have to adapt to the specificities of these services. In particular, this will require a focus on outcomes (e.g. average wait times) versus strict service delivery (e.g. on-time performance).

\section{Mitigate innovation risk for new services through pilots and portfolio management}

Public authorities must ensure that public expenditure delivers value to citizens. This is understandable, but can also hamper their ability to engage in innovative arrangements where the value for the public is initially uncertain. Time-bound pilot projects contain this risk, and many jurisdictions in the United States have used these. Public agencies might also create public-private "innovation laboratories" that manage a portfolio of new projects to help identify interesting initiatives. National authorities can help as well, by creating dedicated programmes to help fund trials that have the potential for widespread replication. A good example is the US Federal Transit Agency's "Mobility on Demand Sandbox" programme. Another option to avoid the risk of lock-in with single service providers is for public authorities to implement user-side subsidies rather than supplier-side subsidies.

Incentivise age- and disability-friendly interactions in partnerships between public transport and ride-service operators

Ageing has a major influence on disability trends. These, in turn, will have an impact on the ability of an ageing population to remain mobile and enjoy good access to services, opportunities and other people. Many older people are affected by impairments including loss of visual acuity, loss of hearing, short-term memory loss or difficulties in balancing. The design and delivery of partnerships between public transport and ride services must take this development into account so as not to exclude older people and those with disabilities. Public authorities should generally ensure that innovative services meet the needs of the population as a whole on an inclusive basis. Incentives for ride-services to deploy wheelchair-accessible vehicles, appropriate levels of training for drivers, call centres for bookings and questions for users with special needs and innovative contracts between operators and public authorities to improve para-transit services (like in Boston) are examples for how this can be achieved. 


\section{Introduction}

The past few years have seen the rapid global deployment of new types of mobility services that leverage advances in ubiquitous computing, geo-location, cashless payment. These services, ranging from car- and bicycle-sharing, app-enabled on-demand micro-bus services, and platforms that connect travellers and drivers, are starting to significantly disrupt the mobility landscape of cities around the world. Even though the most visible of these - ride services like those offered by Didi Chuxing, Grab, Lyft, Ola and Uber - have had an important impact on global taxi markets, they still only account for a relatively small share of trips in most urban areas, especially compared to trips taken by car, walking and cycling, and public transport.

In San Francisco, one of the cities where uptake of app-based ride services like those offered by Transportation Network Companies (TNCS) Lyft and Uber has been strongest in North America, these services account for $2 \%$ of all trips though about a quarter of all residents use these services at least once a month (Figure 1). Recent analysis from New York City indicate that additional travel generated by TNCs account for 3.5\% of overall distances travelled by all vehicles in 2016 (Schaller, 2017) (see also Box 2).

\section{Figure 1. San Francisco Bay Area mode share (2015)}

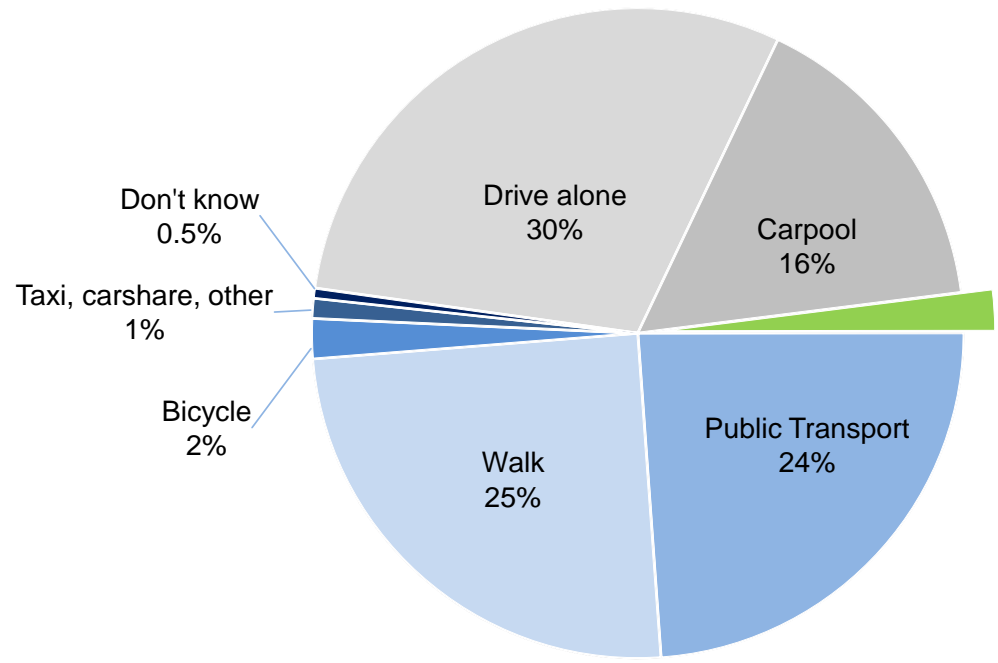

Transportation Network Company (TNCs) $2 \%$

- Women use TNC's proportionally more than men ( $3 \%$ and $1 \%$, respectively)

- Travelers aged 18-34 y.o. use TNCs proportionally more than those aged $35-54$ y.o. and $55+y .0 .(3 \%, 2 \%$ and $1 \%$ respectively of all trips for each age group).

- Those with incomes over $\$ 75 \mathrm{k} / \mathrm{y}$ use TNCs proportionally more than those with lower incomes ( $3 \%$ vs. $0.5 \%$ ).

- In terms of newer mobility options (TNCs, carshare, bike-share, shuttle services, etc), TNC's are the most used of the new travel options with $23 \%$ of respondents overall, $28 \%$ of San Francisco residents and 17\% of other Bay Area residents saying they use it at least monthly.

- Of the other newer transit options, $12 \%$ percent have tried Car Share; about 3\% have tried Bay Area Bike Share, and about $2 \%$ have tried Chariot - an app-enabled route-based shuttle service.

Source: San Francisco Municipal Transportation Agency (SFMTA), Travel Decisions Survey (2015).

Despite accounting for a small share of urban trips, the popularity of app-based ride services is evident in the rapid growth of trips in metropolitan areas where they are present, the growing volume of application downloads, the increase of new cities serviced and in the number of competing services offered around the world. Behind the popularity of ride services is the convenience and flexibility they afford both their users and their drivers. This popularity suggests that these services may not only continue to have an impact on for-hire markets, but that they may also likely disrupt public transport markets in significant ways. Their ultimate impact on urban transport, especially when combined with advances in automated driving, may be game-changing since some of the major players in this emerging field have indicated that their goal is to deliver most urban trips in the future.

Public transport operators have typically not dealt in the kind of diffuse and fractional capacity supply provided by many new ride services and, with some rare exceptions, have not typically seen developing these markets as part of their core mission. The convergence between traditional public transport operators and many ride-sourcing and ride-sharing services, however, is no longer just a theoretical possibility. Some 
public transport operators and authorities have already, or are currently in the process of exploring partnerships with new, app-enabled mobility services.

There are important lessons to be learned for the governance of public transport from the on-going confrontation of ride services with, and adaptation of, rules regarding for-hire transport. The report "Unfinished Business: A Blueprint for Uber, Lyft and Taxi Regulation" notes:

The history of taxi regulation shows the potential peril from poorly constructed regulatory frameworks. The product of decisions made over several decades, taxi regulations served to limit competition and innovation, compromise the quality and reliability of cab services and as a result, limited the taxi industry to niche markets centered on business travellers and non-car owning households. (Schaller,2016)

Similarly, certain types of public transport may become marginalised in the face of new forms of mobility services that public transport operators may fail to understand and account for. This is unfortunate since there are many areas where traditional public transport operators can seek synergies with emerging ride services.

The convergence of public transport and ride services in particular could potentially deliver better mobility outcomes for a broader share of the population than currently feasible. Yet at the same time it poses clear risks to the provision of equitable and sustainable mobility for all. These risks include replacing well-understood business models and the regulatory framework governing them with a greater reliance on services whose business models are in flux and whose long-term financial robustness is not yet proven. There is also a risk that a shift in service from traditional public transport to ride services could lead to a loss of travel options for those with mobility impediments since ride services currently do not face the same accessibility requirements as public transport. Other risks could include increased congestion and environmental degradation and an erosion of equitable access opportunities. These and other risks are only potential; and in some cases, they may be overstated since the case can be made that mobility outcomes may greatly improve through this convergence. Nonetheless, they highlight the need for properly framing the policy principles that should guide action in this area.

This report investigates motivations guiding the convergence of ride services and public transport, the role public authorities can play to ensure that this convergence supports both commercial innovation and public policy objectives and what set of principles can usefully guide partnerships between innovative mobility services and public transport operators. In addition, this report explores where action may be needed to ensure that this convergence does not lead to reduced mobility options for those that have difficulty using existing transport modes, and in particular, how the needs of an ageing population may be met in an evolving mobility service landscape. It builds on similar work published in 2016 in the International Transport Forum's Corporate Partnership Board report "App-Based Ride and Taxi Services: Principles for Regulation" (ITF, 2016a). 


\section{Getting around cities: Then, now and in the future...}

Urban travel patterns differ around the world, between different cities and amongst different demographic and income groups. People travel for different reasons, at different times and with more or less flexibility in their trip-making choices. They also value trips differently according to convenience, speed and willingness to pay for these and other features. And yet, despite these differences in individual trip-making patterns, there are global similarities that broadly characterise urban transport. These include a choice-set that has traditionally included walking and cycling, various forms of formal or informal public transportation and individual motorcycle or car use. Historically, and in many developing countries today, as incomes rise there is a general trend away from the former modes to the latter.

Urban mobility is the sum total of people moving in and around urban areas to access opportunities, to gain access to each other and to gain access to the goods they wish to consume or the movement of goods to their final point of consumption. The movement of people and vehicles through cities is perhaps one of the most dynamic and noticeable features of urbanisation. Mobility, and the access it confers, is essential in delivering agglomeration benefits that result from people crowding together in urban regions. It is also an enduring and significant source of frustration and dis-benefits linked to the erosion of the very benefits it helps support. Managing congestion, eliminating traffic injuries, reducing noise and environmental impacts and improving equity outcomes all are integral public objectives that guide policy in this field.

\section{Traditional urban transport modes: Limited choices, broad uptake}

Mobility has historically been delivered by a relatively limited set of travel modes and options: active modes (walking and cycling), formal and informal public transport and individualised motorised modes covering two- and three-wheelers and cars. For the better part of the last half-century, this choice set has been constant across the world albeit with each mode accounting for a different share across regions, in time and for various trip purposes.

There are a number of reasons that people choose one mode over another but at the heart of these choices is the expected and achieved outcome and user experience. These aspects, in terms of speed, comfort, safety, cost, accessibility, reliability and convenience, are critical in determining demand for transport services, at least when there is a choice of alternative ways to travel (ITF, 2014). The relevant measure of user experience extends beyond each individual trip to the entirety of the oftentimes complex trip chains that characterise everyday travel. In the end, people generally choose the mode that best fits the a small subset of their overall daily trips, either because those trips are the most important or are those for which the fewest acceptable alternative modes exist, and then use that mode for all trips out of both convenience and habit.

The relative simplicity and flexibility of individual motorised travel helps explain why cars dominate travel within many urban regions (especially outside the core) across the OECD member countries and are making rapid inroads in rapidly-developing economies around the world. While car travel in certain high-income countries has stagnated or has even decreased recently, many people have grown accustomed to the convenience that at least occasional car travel confers.

Convenience (e.g. faster, on-demand, perception of low cost) is one of the strongest attractions of private cars and motorised two-wheelers in cities. Because they offer flexible and on-demand door-to-door travel opportunities, people generally value car-based mobility highly; they are willing to put up with its cost which is higher than walking and cycling, and often higher than the consumer-facing price of many public transport services. They are also willing to overlook inherent inefficiencies (in terms of poor capital use given the amount of time cars remain idle, energy efficiency and time losses due to traffic congestion at 
peak use periods) because of the utility they derive from travelling with these modes. This helps to explain the persistent attraction that people have for acquiring and using cars. Associated with this preference, many people in mid- to highly-motorised regions have made housing, employment and lifestyle choices that require some level of access to cars.

In all of these contexts, e.g. where car use remains elevated or is becoming more popular, there will be pressure to prolong driving as long as possible in life. At the same time, those who lose the ability to safely operate vehicles may see a reduction in their mobility options and access - especially if they live in areas that are difficultly served by other modes. This has important policy repercussions when considering how to ensure high-quality access and mobility for all, while not eroding overall gains in road safety as a result of retaining older drivers who may no longer be able to safely operate cars.

Some see the eventual arrival of self-driving vehicles - especially those operating as shared mobility fleets (see ITF, 2016) as one way around inequitable outcomes that may arise if people are no longer able to drive cars and do not have high quality alternative options. Automated vehicle technology can potentially prolong car-like mobility for many, but it is not a panacea. It will require careful framing in order to not erode commonly shared public policy outcomes (e.g. congestion mitigation, use of public space, energy and environmental impacts).

Taxis provide many of the benefits of individually-owned car mobility albeit at a higher price for consumers and oftentimes lower convenience than cars. This lower convenience generally stems from the lower flexibility and availability of taxis as compared to cars, although in certain dense urban environments with elevated parking costs, taxis - especially street-hailed taxis - have provided an attractive urban mobility option. Taxis therefore have historically become a means for those not familiar with a city to get around, for wealthier travellers to get around where car use may be inconvenient and as a way of filling the gap in public transport provision for those who do not have access to cars - especially in off-peak hours and to destinations not well-served by public transport.

Public transport - e.g. openly shared passenger services that are available to the general public - offer essential mobility services in urban areas. These include the efficient provision of large-scale and mostly frequent passenger transport across fixed-route networks that would be difficult and, in many cases, impossible to provide otherwise. These services make living in urban areas highly convenient though in many cases the fixed nature of both networks and schedules may make public transport itself not necessarily convenient. This is especially the case if travel to destinations includes transfers and significant waiting times. Public transport also provides basic mobility to those who may not have access to cars and whose travel requirements are not suited to walking or cycling.

Public transport thus serves different populations and is characterised by different levels of service and quality. High-frequency, rapid and good quality public transport supply may compete with cars in terms of convenience, cost and overall user experience. It does so while decreasing per-passenger land-take, energy use and environmental impacts due to efficiencies derived from scale and electrification in the case of many rail, trolley and electric-powered bus systems. As such, these types of public transport networks represent an essential component in delivering more sustainable urban transport options.

Where investments in public transport have been consistent and accompanied by land-use decisions that concentrate populations in easily-serviced areas, core public transport networks are generally well-used and account for a significant mode share. These central networks (including both well-used rail and bus lines) typically provide good service between large residential areas and employment centres, especially at peak hours. As such, they best serve commuting trips. Other travel, especially that occurring off-peak and in lower density areas outside of these key corridors, may be more difficult to service cost-effectively. This is especially the case for trips connecting the first and last kilometres to core public transport networks. 
Delivering these trips is generally an expensive proposition for public transport operators and often requires some form of cross-subsidy from other more profitable services or a direct payment from public authorities.

There are real equity stakes at play since public transport services focusing primarily on peak travel along core networks may not adequately respond to the mobility needs of certain demographic and or geographic groups. Women generally have complex trip-making patterns that extend beyond the pendular commute trip. Public transport, especially in low-density urban and suburban areas, may not provide as convenient a service as cars in those instances. Many low-income workers are employed in the service sector, manufacturing jobs or in part-time employment. These jobs may be located in areas poorly served by public transport or may have schedules that are incompatible with public transport services. For these populations, a car, when they can afford it, may be the most convenient option - and a taxi, an expensive but sometimes convenient choice.

Historically, public transport started as relatively informal systems and this continues to be the case in many countries today, especially in Asia, Africa and Latin America. Informal public transport systems (e.g. jitneys, collectivos, matutus) have a range of characteristics that may compare favourably or unfavourably with formal public transport systems. They generally have unpublished (or inexistent) schedules and routes, and may change service frequently. They are largely unregulated and thus may not be safe nor offer sufficient consumer protection. On the other hand, these services offer great flexibility at affordable rates for many inhabitants. As micro-enterprises, they also offer a non-negligible source of income to their drivers. The history of public transport is marked by the gradual formalisation of these types of services to improve co-ordination, safety and transparency but this has come at the expense of convenience for many users of these systems. Tellingly, many ride services mimic several of the beneficial characteristics of informal transport systems while delivering better safety and consumer outcomes, albeit at higher costs.

In many OECD member countries, public authorities seek to ensure that as many people as possible are afforded meaningful mobility options and are not excluded from participating in essential activities due to physical or other impediments. The right for equitable access is codified in law building on the example of the Americans with Disabilities Act (ADA) of 1990 (USA) and the U.N. Standard Rules for the Equalization of Opportunities of 1993.

For public transport, this has led to requirements to provide services for those with a wide range of physical or cognitive impairments. Paratransit services ensure a minimum coverage of accessible services for those qualifying to use them but this coverage comes at a significant cost to the public authorities that subsidise them - often at levels several times that of traditional public transport due to the need for specialised equipment, dedicated vehicles and well-trained drivers. In the United States, paratransit services cost on average 3.5 times the cost of providing a regular public transport trip (Kaufman et al., 2015) and these costs are increasing as a greater share of the population ages into impairments that require specialised services and/or accessible vehicles. Paratransit services are also typically more cumbersome to use than traditional public transport (requiring reservations hours and up to a day in advance) and are in some cases less dependable.

Because of the high and growing cost of providing mandated paratransit services and the desire to ensure high levels of equitable access, many authorities are seeking to make the general public transport fleet accessible to all but the most physically challenged travellers. The same is true for taxis with disability-accessible requirements, ranging from a percentage to the whole of the fleet. In many instances, those travelling with physical or cognitive impairments do not require the use of an expensive, dedicated, wheelchair-accessible vehicle but could benefit from improved accessibility in other transport modes combined with better trained operators. Thus in those regions where providing such a broad level of access has been a focus, public transport and taxis represent important complements to the dedicated paratransit fleet and deliver essential services to mobility-challenged travellers. 


\section{Innovative mobility options: More choices but an uncertain future}

The set of mobility options that have characterised most cities in the world has expanded in recent years with the appearance of many new public and private sector services. New business models including carand bike-sharing, ride-sourcing and ride-sharing have become possible thanks to advances in technology, algorithmic skill, ubiquitous internet access and the broad uptake of mobile computing and smart phones. Not all of these services are new - in some instances, they have given new life to existing services like on-demand public transport. As these services become more popular, they both complement existing services and provide new alternatives for many travellers. The set of emerging mobility options is constantly evolving as are the companies or partnerships providing them.

Many evolving and shifting business models

The rapid spread of these services and their sometimes unpredictable evolution underscores the limited capacity of classic modal-based approaches to address them, especially approaches that focus on a strict dichotomy between public and private transport. At least on a strategic level, policy can be better served by focusing on outcomes rather than focusing on the delivery of specific services. In so doing, public authorities and private operators will need to account for the growing diversity of options that can be mobilised to improve mobility and access outcomes. In this context, perhaps a more relevant conceptual lens for this century's urban transport systems is between transport using one's own vehicle and transport provided by personalised or shared services.

The innovative mobility ecosystem is complex and combines multiple conceptual models that bring a much wider range of actors into play than before. Capturing the diversity of innovative mobility services is not straightforward since business models are constantly evolving and new services are continually being trialled - even within individual companies. These models may include formal business-to-consumer services (commercial car-sharing, micro-transit, bicycle and scooter sharing), peer-to-peer models for sharing the use of cars or that enable the sourcing of rides, platform-based business models that connect passengers and drivers (or goods and carriers) and hybrid models that combine aspects of some or all of those approaches (Shaheen et al., 2016a).

From a policy perspective, the diversity of new actors and business models, their rapid flux and evolution and the many potential deployment pathways complicate the task for public authorities seeking to create new partnerships. This is especially true for transport authorities that are operating or contracting/procuring services from relatively stable and established public transport operators.

At present, the evolving mobility landscape in many cities around the world includes some or all of the types of services outlined below and largely drawn from the work of the Transportation Sustainability Research Center at the University of California, Berkeley (Shaheen et al., 2016a; 2016b).

\section{Bicycle-sharing}

Bicycle-sharing allows members and users to access bicycles that are available in public space. Analogue bicycle-sharing systems have been around for decades but the arrival of IT-enabled, automated bicycle-sharing systems has led to massive growth. In 2016, approximately 2 million shared bicycles were available in second generation or later systems in 63 countries and in over 1000 cities, municipalities or district jurisdictions (Demaio, 2017). In sufficiently dense networks and where provisions have been made to increase bicycle safety, bicycle-share systems can improve access and extend the reach of traditional public transport networks.

Shared bicycle systems require registration and payment is ensured via various subscription or time-based fees. There are several bike-share models. Currently, bike-share systems are dominated by dock-based networks where bicycles are picked up and returned at specific stations. These systems must address some 
inherent challenges that have an impact on their viability, including deploying a sufficiently widespread and dense network of stations and cost-effectively handling system-wide rebalancing needs. An alternative, emerging model for bike-share is centred on dockless fleets of bicycles that can be picked up and dropped off anywhere within a within a geo-fenced zone. In these instances, bicycles come equipped with on-board GPS and communications equipment. Some peer-to-peer services also exist. Most IT-enabled systems have proprietary apps that enable users to find bicycles and drop-off locations. In some cases, open application programming interfaces (APIs) allow third party developers to include bike-share data in their applications. A standardised bicycle data model - the General Bikeshare Feed Specification (GBFS) - has been developed in order to facilitate data-sharing and inclusion of bicycle share data in modular APIs. This specification is modelled along the lines of the General Transit Feed Specification (GTFS) and may facilitate the integration of bicycle-share services and payments with other bundled mobility services.

\section{Car-sharing (and scooter-sharing)}

Car-sharing services allow members to access cars for individual trips or short periods of time. They require registration and can be paid on a per-use, per-time or on a subscription basis. As with bicycle sharing, car-sharing has a relatively long history in its pre-digital form but its success has really taken off with the transition to online and digitally-enabled platforms. As with shared bicycles, they can be station-based or free-floating. In both instances, data is generated and logged in order to manage payment and system operation. Some systems share this data through APIs that offer some level of integration with third-party service providers.

Car sharing fleets can be commercially owned business-to-consumer ventures though there are many services that facilitate peer-to-peer car sharing. In some instances, car-sharing may be bundled with other mobility services (e.g. agreements between Mobility Car Sharing and the Swiss Federal Railways). Both the range of actors involved in various forms of car-sharing and their business models are in flux with many traditional rental car companies and automobile manufacturers creating, purchasing or taking stakes in car-sharing companies. Common data standards might facilitate the bundling of car-sharing services with other mobility offers (including first- and last-kilometre public transport) but these are currently lacking. Though it is too early to tell, vertically integrated models where some form of car-sharing is embedded in a suite of other mobility services offered by a single company seems to be an approach favoured by major automotive companies.

Much along the lines of car-sharing business models, some companies offer scooter-sharing services that are typically free-floating rather than station-based.

\section{On-demand micro-transit}

Many public transport companies, especially in low density areas in Europe, have offered on-demand public transport services as a way of reducing the costs of fixed route services in thin markets. One example of a comprehensive, national implementation of such a platform-enabled on-demand marketplace is FlexDanmark (see Box 1). This system builds on regulatory requirements to ensure health- and education-related accessibility across the country to create a nationally co-ordinated and optimised on-demand transport facilitated by a common IT platform. By centralising information on demand and creating a marketplace to provide flexible supply, it enables specialised trips (medical, school, etc.) to be carried out more efficiently and at lower cost than by traditional services and allows other trips to be carried out by shared vehicles rather than by single occupancy cars or large poorly-utilised buses.

Taking advantage of new technological possibilities and in part inspired by informal public transport systems around the world, some companies have developed app-enabled shared micro-bus services that replicate the flexibility of car-based travel (or taxi and ride-sourcing) in certain markets (e.g. Chariot, Didi Bus, Grab Shuttle, Ola Shuttle, Via or Ford's Go Ride service). Multiple business models supporting these services 
have been developed and they encompass different approaches to service design. For example, some operate fixed routes that are in-part crowd-sourced by users (e.g. Chariot - see Figure 2) and others offer services where riders are directed to pop-up stops within defined geographic areas. Some companies, like Chariot, offer a mix of crowd-sourced fixed-route services alongside point-to-point travel. For example, the Chariot Direct service runs counter to dominant commuting flows in San Francisco as a way to offer more flexible options for commuters heading away from downtown and to help rebalance (and monetise) Chariot's fleet. Market entry and zone coverage is also handled in many ways. Bridj, an app-based micro-transit operator no longer in operation, gauged market entry based, in part, on app downloads and adjusts its service zones dynamically by analysing service requests from riders. Chariot, on the other hand, mixes pre-set routes based on obvious trip-generating and trip-ending destinations with crowd-sourced routes requests and new account sign-ins. Cashless payments, reserved seating, transfer-less rides and geo-localised customisation are all part of the user experience for services whose public-facing cost is somewhere between traditional public transport and ride-sourcing services or taxis.

\section{Box 1. National platform-enabled demand responsive transport: FlexDanmark}

In light of regulatory requirements to ensure public service access for people with mobility impairments, and for medical and school-related trips throughout the country and in light of the elevated cost of doing so via fixed-route bus services - especially in rural and peri-urban areas - a number of Danish transport operators and authorities joined forces to put in place a nationwide IT platform and service offer for cost-effective and high-quality on-demand transport - Flex Traffic operated by the mixed public-private company FlexDanmark.

The service is built on demand-responsive buses and mini-buses, and for-hire vehicles and taxis ordered from the online platform or from call centres. The centralised dispatching platform allows for contracting across multiple agencies and operators and ensures more efficient pooling of resources and improved services for riders. In 2015, the Flex Traffic provided 5424670 trips for 240910 unique individuals using 5162 vehicles belonging to 773 operating companies; 545 public authorities participated in the service.

At its core, Flex Traffic has facilitated the evolution of the role of the public transport organisations (PTOs) in Denmark from control and enforcement of operators to one of auctioneer of services thus maximising quality and productivity. Through the platform, PTOs buy resources (taxi and bus service) from private companies, and, combined with all the planned trips - generated through different remote online ordering modules used by a number of authorities - optimise the utilisation of that capacity in real time. Because of volume discounts and auctioned prices, the PTOs realise cost-savings compared to if they had purchased these services through more traditional procurement routes.

The Flex Traffic procurement model is two-pronged, comprising of a spot-market for services and a longer-term fixed service contract. The spot-market seeks to ensure bids aligned with the lowest generalised cost on the basis of unit-prices (EUR per vehicle hour) submitted by operators every year alongside other factors including estimated trip distance and duration, proximity to the customer requesting the service, special needs the customer may have and the quality rating for participating hauliers. The longer-term market is comprised of two- to four-year contracts guaranteeing a minimum availability and quality assurances.

Because it is platform-based and outcome-oriented, the Flex Traffic approach represents one way in which authorities can create an open market for paratransit and ride service trips that support public objectives.

Source: Adapted from Larsen (2016).

Private shuttle services also offer bespoke public transport-like services to their users. These are not open to the public but in some regions and for some destinations may have non-trivial impacts in terms of mobility outcomes (when a significant share of workers use them) or on the performance of other transport modes (if they impede traffic or access to kerb space). Company-organised shuttles between San Francisco and Silicon Valley are perhaps the best known of these private "shadow" public transport networks but other examples exist including shuttles connecting residential zones to business and technology parks in India or in Singapore, or linking rail stations to industrial parks in many European cities. 
Figure 2. Chariot app-based on-demand micro-transit routes in Austin, Texas

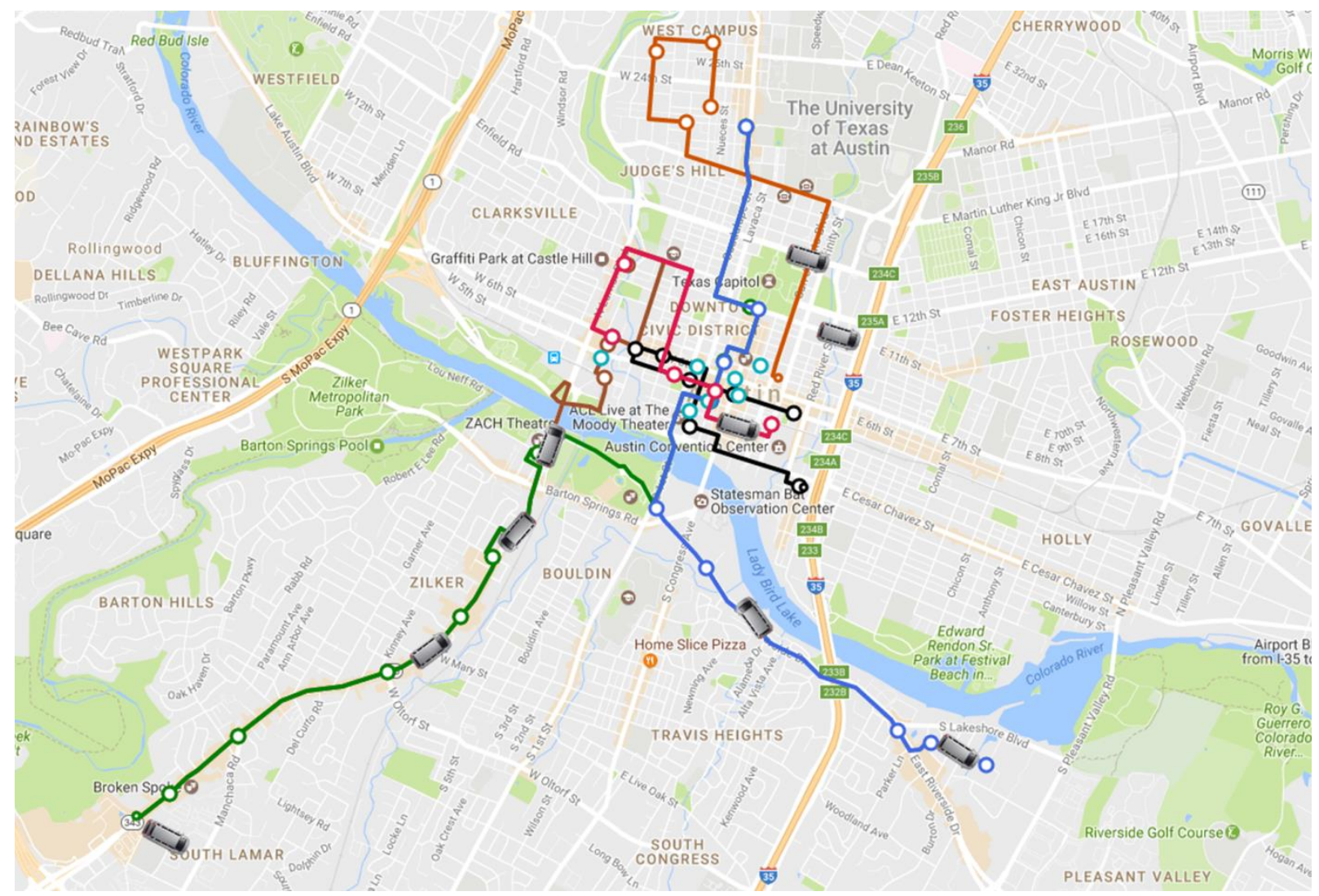

Source: Chariot.

\section{Ride-sourcing}

Perhaps the most visible new entrant in the urban mobility space has been commercial ride-sourcing services (categorised as Transportation Network Companies - TNCs - in California law and often referred to as such in the North American context). These include companies operating in local, regional and global markets (e.g. Didi Chuxing, Grab, Lyft, Ola, Uber) that have rapidly and in some cases significantly disrupted taxi markets.

The ride-sourcing business model centres on an app-enabled platform that facilitates transactions between registered users and vetted drivers. The model has proven extremely attractive to both users and to drivers and the convenience it provides replicates many aspects of car ownership and use. The model's success rests on the technical skill with which the platform matches demand and optimises the allocation of vehicles as well as on the ability to mobilise a sufficient number of drivers to ensure low wait times. Its commercial success depends on lower consumer-facing prices than taxis which, at present, largely stems from lower driver costs as compared to other options. It also depends on offering a flexible enough, attractive and remunerative option to attract sufficient drivers.

Though the technological backend of these services is sophisticated, it is not overly complicated to replicate. The field of ride-sourcing services is expanding with some concentrated on niche services, some in regional markets and at least one with a global presence. And new entrants are arriving all the time: eCab is a taxi-based ride sourcing platform expanding in Europe; Abel is a ride-sourcing service offered by TransDev in the Netherlands; and zTrip is TransDev's ride-sourcing platform offered in a growing number of 
North American cities, including in Austin where Uber and Lyft have both pulled out following a dispute with the local authorities on applicable driver security checks.

Pricing is typically calculated on both trip duration and distance and many companies also apply variable pricing to incentivise drivers coming into service at peak times and locations and to moderate demand (e.g. "surge pricing" or "prime time" fares). The principal cost component of this service is related to driver compensation which has led to speculation, confirmed by market actions by several leading companies, that ride-services may seek an early uptake of vehicle automation. Such a move might change the business model behind ride-sourcing (and ride-sharing - see below) from one based on a technology platform connecting riders and independent drivers to one based on a company-owned, operated and managed fleet of automated vehicles. If this were to happen, the service delivery model of ride-sourcing may more closely resemble that of company-owned and managed public transport fleets.

The ride-sourcing model has clearly disrupted the status quo in the cities where it has been introduced and several well-publicised regulatory and legislative battles have accompanied its spread. These typically centre on how to both license ride-sourcing services and address the possibility of unfair competition with other service providers. The arrival of ride-sourcing services has raised questions regarding the vetting of drivers and how to treat them from the perspective of labour law, as well as regarding the taxation status of drivers and platforms. Some public authorities have also raised the point that, unlike public transport and taxi services, ride services do not face requirements to provide accessible vehicles or ensure equity outcomes, in particular regarding geographic coverage. The success of ride-sourcing services in many metropolitan areas has led authorities to question whether their impacts on traffic may indeed outweigh the mobility benefits they confer to cities. This has led some authorities to seek detailed data from companies that may or may not be requested from other mobility service providers - or car drivers - on the same markets. Recent investigation of this data for New York City, for example, shows mixed results as far as the impact of ride services at an early stage of their deployment in that city (see Box 2).

In many instances, ride-sourcing offers a very flexible alternative to public transport and taxis (albeit more expensive than public transport) and could theoretically help reduce the need or attraction for car ownership. For this reason, some authorities are actively trialling partnerships with ride-sourcing companies in order to both lower the cost of public transport provision and to improve mobility outcomes for those who cannot, or choose not to, drive cars. It is also important to note that because ride-sourcing companies are currently more flexibly regulated than public transport and taxis in many markets, they are able to trial new services and business models - including some that have become quite popular, like commercial ridesharing. 


\section{Box 2. Traffic and other impacts of ride services in New York City}

Independent third-party analysis of ride-service impacts has been limited in cities where these services have been deployed. One reason for this is that ride service operators understandably want to preserve commercially sensitive and privacy-eroding data - especially in light of the obligations that some public authorities have to make public data they hold. Ride service companies have faced calls for detailed data release that they have sometimes accepted. At least one company, Uber, has created an on-line tool, Movement, allowing registered users to access some of the data Uber collects. One exception to the general rule of limited data sharing by ride services is New York City, where the city's Taxi and Limousine Commission (TLC) compels ride services to provide detailed data analogous to the data that taxis and other traditional ride services must provide. Former New York City Deputy Commissioner for Traffic Planning and Taxi-Transportation Network Company (TNC) expert, Bruce Schaller, analysed this data and released a report in February, 2017, highlighting what these reveal in terms of traffic and other impacts the growth of ride services have had in New York City.

Though data are available for taxis, TNCs and other ride services, as of 2016 comparison was difficult because reporting requirements were not the same for each category. In particular, taxi data includes pick-up and drop-off location, date, time, distance, duration and fares. TNC data, on the other hand, only includes date, time and pick-up location, though TNC data for selected months in 2014 and 2015 include trip destination, duration and distance. New requirements for TNC reporting will include destination and duration from 2016 on. These data discrepancies are important to understand since, in the absence of fully comparable data (especially as regards travel distances), the report estimates traffic impacts on the basis of other data sources, including aggregate travel distance data gathered from ride service odometer data.

Findings from this analysis indicate that TNCs have become an important and fast-growing part of the city's transportation system. In 2015 and 2016, they have been the leading source of growth in non-auto (i.e. non-personal car) travel in the city. They have also added significantly to vehicular travel and mileage on city streets. Key findings of the report are:

- $\quad$ TNCs transported 15 million passengers per month in Fall 2016 - nearly as many trips as served by the city's yellow cab industry - in 43000 licensed vehicles.

- $\quad$ TNC ridership tripled between June 2015 (the end of the period examined by the City of New York's For-Hire Vehicle Transportation Study) and the fall of 2016.

- After accounting for declines in yellow cab, black car and car service ridership, TNCs have generated net increases of 31 million trips and 52 million passengers since 2013.

- In 2015 and to an even greater extent in 2016, growth in taxi and for-hire ridership outpaced growth in transit (subway and bus) ridership and is now the leading source of growth in non-auto travel in New York City. This marks a reversal from the transit-oriented growth that lasted from 1990 to 2014.

- $\quad$ TNCs accounted for the addition of 600 million miles of vehicular travel to the city's roadway network over the past three years, after accounting for declines in yellow cab mileage and mileage in personal vehicles. The additional 600 million miles exceeds the total mileage driven by yellow cabs in Manhattan.

- Total mileage of TNCs, yellow cabs, black cars and car services combined increased from $14 \%$ to $19 \%$ of total citywide mileage from 2013 to 2016. (The industry mileage includes transportation of passengers, "dead-head" miles between dropping off one passenger and picking up the next passenger, and drivers' personal use of driver-owned vehicles.)

- In Manhattan, western Queens and western Brooklyn, TNCs added an estimated 7\% to existing miles driven by all vehicles, an increase of the same magnitude as the 2007 congestion pricing proposal would have decreased vehicle miles travelled (see Figure 3 ).

- $\quad$ Since mid-2015 TNCs have offered and heavily promoted "pooled" options such as UberPool and LyftLine. TNC mileage nonetheless continues to grow rapidly because exclusive-ride trips still predominate, and because most TNC customers are coming from public transport, walking and biking. Migration from public transport translates to increased mileage even if the trips are shared.

- Growth in trips, passengers and mileage is seen throughout the city as TNCs attracted yellow cab riders, those who would otherwise use the bus, subway or their personal vehicle, and people who would not otherwise have made the trip. 


\section{Box 2. Traffic and other impacts of ride services in New York City (continued)}

- $\quad$ Trip growth in Manhattan has been concentrated during the morning and evening peak periods, when yellow cab shift changes produced a shortage of cab availability, and late evenings and weekends when passengers may prefer the comfort and convenience of TNCs over yellow cabs or transit services.

The report finds that a continuation of the type of TNC-led growth in travel the city has experienced in recent years is not aligned with sustainability objectives (mobility, economic growth, road safety, environmental) that the city has set. Nonetheless, the correlation the report observes with the rise of ride services and a decline in public transport ridership may not necessarily be a causal one as there are other potential explanatory factors. These other confounding factors include the drop in gas prices since 2013, which has a well-documented statistical relationship with transit ridership and an increase in the prevalence of public transport delays in the city over this period. Other issues to consider may be the reports reliance on mode share data for trips that pre-dates the uptake of ride services, the degree of pooled ride service share and the possibility that since the bulk of ride service growth occurred in the outer, more car-dependent, boroughs of the city, many new ride service trips may indeed have disproportionately replaced single occupancy vehicle trips.

While these findings are specific to New York, the report does note that there are lessons to be drawn for other similar cities. The local context will also matter insofar as specific impacts are concerned. For example, in cities with (relatively) low car use and high public transport, cycling and walking, it seems more likely that TNCs will lead to a transfer from those modes to car-based TNCs and thus lead to an increase in car travel. In cities with a much higher reliance and mode share for single-occupancy car travels, traffic impacts may be less marked as TNC riders would switch from single car use to TNC trips.

The report identifies a variety of steps to address the rising attractiveness of TNCs while also supporting the mobility benefits that TNCs clearly offer. These include many initiatives already underway to improve the speed, reliability, comfort and ease-of-use of bus and subway service and the comfort and safety of cyclists and pedestrians. The report also finds that continued TNC growth, particularly as that growth becomes increasingly fuelled by low fares, will raise the broader issues of road traffic management, including, through the use of road pricing.

The report notes that New York City authorities have historically used pricing of taxicab fares and parking to discourage auto use in Manhattan. As they steadily cut fares, TNCs are erasing these longstanding financial disincentives for traveling by motor vehicle in Manhattan. The report suggests that if TNC growth continues at the current pace (and it finds there is no sign of it levelling off), the necessity of some type of road pricing will become more and more evident.

\section{Figure 3. Additional travel generated by Transportation Network Companies in New York City (2016)}

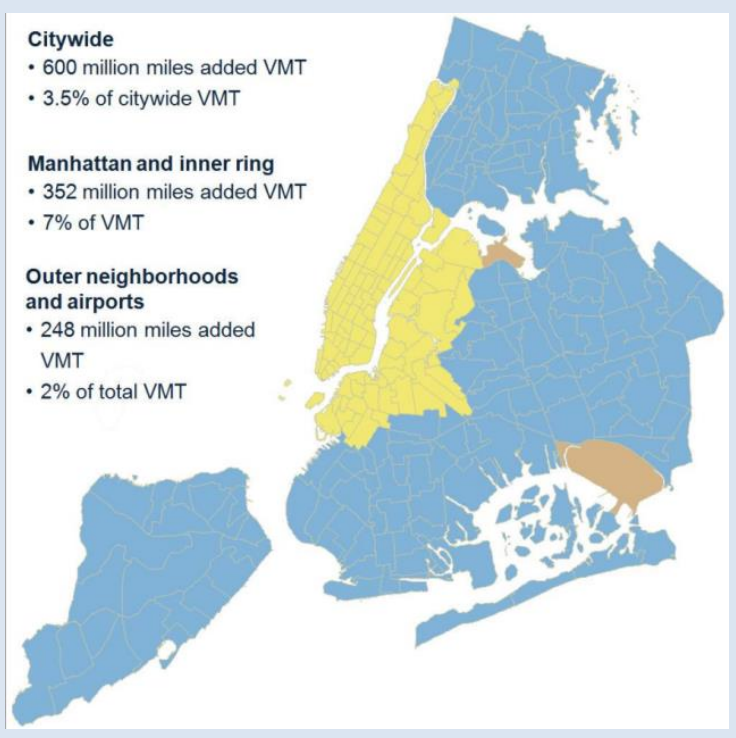

Source: Adapted from Schaller (2017). 


\section{Commercial ride-splitting or ride-pooling}

Some ride-sourcing companies offer commercial ride-splitting, services (e.g. DIDI Hitch, GrabHitch, Lyft Line, UberPool). These function are much like ride-sourcing services except that they match multiple, unrelated individuals or parties to share the same vehicle over the course of the same ride. Ride-sharing algorithms treat ride requests and allocate them in real time to available vehicles such that people get on and off along the trip while minimising added travel distance and trip duration - e.g. the "insertion cost". Because insertion costs are contained and overall costs are split, these services provide a less-expensive option to ride-sourcing and have proven popular in many markets. In some markets, these pooled ride services are cost-competitive with traditional forms of public transport. These services are slightly analogous to micro on-demand transit services although they generally remain door-to-door (and not route-based) and typically use smaller vehicles. In some cases, access to ride-sharing services has been bundled into a monthly subscription package (e.g. Lyft Line and UberPool pass trials).

Ride companies have tested a number of shared ride services based on fixed routes - for example, Uber's Smart Routes in San Francisco and Chicago and Uber Hop in Seattle. In March, 2017 Lyft announced a trial of its fixed-route shared service "Lyft Shuttle" in Chicago and San Francisco. It will offer fixed fares and no peak demand surcharges unlike other Lyft Line services. These initiatives indicate that ride service data reveals a potential for aggregating riders with common departure zones and destinations into shared fixed route lines - operated by cars now but potentially involving minibuses in the future thus shifting towards the on-demand micro-transit models described earlier. This shift also reveals potential for hybrid services to develop that may be the basis for more formal and structured relationships with public transport operators and authorities.

\section{Maps, routing apps and services}

Web or app-based mapping services have rapidly become an essential element in urban travel. Initially providing mapping and routing information to help plan travel, they now combine real-time data on travel conditions, available travel options and, in some cases, allow for remote booking of transport services in response to itinerary requests. These apps can be purely third-party providers that consolidate and display travel options from a number of other sources in dedicated way-finding apps (e.g. Citymapper, Moovit, TransLoc). Map-based platforms like those offered by Apple, Baidu, Bing, Google and Naver have also tapped into public transport, ride-service and other mobility provider APIs to offer alternative itinerary choices to travellers differentiated by route, cost and travel times. In some cases these third-party apps or platforms calculate and offer mixed-mode itineraries that combine public transport with other mobility services (e.g. bicycle-sharing and bus, or a ride service and the subway). In-app booking is not restricted to mapping and navigation apps. Some social media and communications platforms allow for instant ride-service booking from within the chat application (e.g. WeChat in China, KakaoTaxi in Korea). From a practical perspective, this consolidation of information on available travel modes, especially when combined with a booking option, opens a doorway to more formal service convergence models.

\section{Leveraging new possibilities: "Mobility as a Service"}

Clearly, much of the potential for improved mobility outcomes as compared to today stems from people being able to access the whole range of mobility options seamlessly and reliably according to their specific trip purposes and requirements, preferences, willingness-to-pay and superior user experience, as well as availability of each of those options at the time and place desired by the user. The convergence of and co-ordination among services, business models and disparate actors in today's rapidly evolving mobility landscape may lead to a situation where consumers no longer purchase and use vehicles or depend solely on providers of traditional public transport services to get around. Rather, people would purchase 
broker-bundled subscriptions of trip services delivered by a number of service providers much as they currently purchase bundled internet and telephone subscriptions.

The formal concept of "Mobility as a Service" (MaaS), first developed in Finland, encapsulates this approach that is gaining traction across some public agencies (e.g. Los Angeles Department of Transport, Helsinki Regional Transport Authority). Perhaps more telling is that 9 out of 15 of the world's largest automobile manufacturers (and four out of the top five) have announced a new focus on "mobility services" rather than depending only, or sometimes even principally, on vehicle sales and maintenance. In some cases, manufacturers have stated that a shift to selling mobility services to consumers will gradually become their core strategic focus (e.g. Ford, Daimler, PSA). Other companies beyond the automotive industry have announced visions that centre on rolling out fleets of shared and perhaps automated vehicles that will obviate the need for car ownership in many cities (e.g. Lyft, Uber and Waymo).

At its base, MaaS is not strictly a new concept. Examples already exist of bundled mobility packages bringing together public transport, car-share, taxi, etc., like those offered in Brussels (MOBIB), Hannover (HANNOVERmobil), Montpellier (EMMA), Vienna (Smile), and across Germany via Moovel or Deutsche Bahn's Qixxit. These packages tend to be regionally negotiated and cover different models and are thus not necessarily designed for broad scalability. What is new is the emergence of technology-empowered mobility brokers that can define, assemble and offer compelling packages of reliable multi-modal services in a way that promises to be as compelling an option as private car ownership.

More recently, the city of Gothenburg housed a small MaaS trial project for 70 households from November 2013 to April 2014. Participants purchased bundled mobility services from operators allowing them to tailor their service packages to their needs - though one result of the trial was that many households had unused travel allocations left at the end of every month, perhaps indicating the value of having mobility "on call", similar to cars that lay unused (Hensher, 2017). MaaS Global, perhaps the best publicised "new" MaaS service, has developed a blueprint for developing mobility as a service packages. This blueprint integrates an app-based consumer interface, cross-modal routing algorithms and application programming interfaces (APIs) allowing transport service providers to seamlessly handle bookings and interact within the application space. In this context, MaaS Global serves as a technical platform and as a mobility broker negotiating the on-boarding of all participating service providers. The company has announced the deployment of its first service offers - "Whim" - in Helsinki and the West Midlands in the United Kingdom.

An alternative approach adopted by some automotive equipment manufacturers is to deploy a suite of vertically integrated services that cover a range of mobility options. This approach is illustrated by Ford's move to federate bicycle-sharing (Bay Area Bike Share), on-demand minibuses (Chariot), and ultimately fleets of automated self-driving cars in an enclosed ecosystem. Yet another approach is to offer subscription packages to a range of services facilitated on an on-line ride-matching platform. Both Lyft and Uber are testing subscription packages in selected markets for their ride-sharing products Lyft Line and UberPool. These and other bundled services are likely to play an important role in the convergence between traditional subscription-based public transport packages and new ride services and other emerging mobility options.

The broad uptake of mobility as a service business models will depend on deploying easy-to-use and reliable consumer-facing gateways while at the same time successfully negotiating the back-office co-ordination amongst service providers. The back-office challenge is not trivial and is not solely technological. The physical production of co-ordinated and joined-up services is a complex task but one that is not necessarily difficult to implement. Ensuring reliable service performance is perhaps more complicated and requires building-in redundancies or back-up measures (e.g. guaranteed ride services) for when services break-down. Handling back-office payment options and negotiating revenue allocation amongst participating companies will also be challenging. Perhaps the most daunting task will be to convince people 
to try these packages and to retain them once they have by providing a more compelling value-for-money proposition than public transport (since these services will be more expensive than a public transport pass) and car travel (MaaS will have to offer services that are judged competitive with car ownership and use). It is unclear at this stage where the potential for MaaS market share ultimately lies but, where it is implemented, MaaS will define new service delivery models that combine the best aspects of public transport and novel ride services. 


\section{Shifting the status quo: Where mobility services and public transport are beginning to converge}

Ride-sourcing, commercial ride-sharing and other innovative mobility services have only recently appeared in the urban mobility landscape and yet it hasn't taken long for many to point out the possible synergies between these services and other more traditional public transport options. This is in part because the rise of the range of innovative mobility options is itself often directly related to some of the shortcomings of existing transport options. High costs, long wait times, uncertain quality and limited competitive pressure in the taxi sector has contributed to the rise of ride sourcing and ride sharing in many markets, especially at times and in areas where public transport performs poorly. Bus services, in particular, have a hard time offering quality services in thin markets outside of core routes; a recurrent problem in these markets is to provide a sufficiently compelling and affordable (to both consumers and public authorities) alternative to single occupancy car use. Public transport services may be reduced to a minimum level of "coverage" routes and schedules that provide extremely limited and inconvenient service. The dilemma facing many authorities in low-density areas is that car use and car dependency rises, increasing congestion and other impacts (even in mid-sized urban areas) which, in turn, puts pressure on authorities to provide sufficiently compelling public transport options to attract car drivers. Quite often, such options are unaffordable as currently delivered or undeliverable as currently priced.

So it is understandable that some authorities facing this dilemma have started to experiment with other ways of providing the services currently delivered via oftentimes mediocre public transport options and indeed, have sought to improve mobility outcomes overall through innovative partnerships. The genesis of this convergence between two putatively competitive services comes not solely for the public sector - many early initiatives were launched by ride-sourcing companies based on the realisation that a significant share of their traffic originates or terminates at public transport stops. Public authorities have been instrumental, however, in seeking out more formal partnerships that may eventually mark the urban mobility landscape. The following section looks at a range of experiences in this area as of Spring 2017. Because it catalogues where these partnerships have been deployed, it focuses largely on North American examples where many of these pilot programmes have been initiated.

\section{Promotions, special events and on-off offers}

At a very basic level, some public transportation operators and agencies have integrated a ride-sourcing or commercial ride sharing within their bespoke trip planner applications and web-based portals. Examples include Lyft (and Uber, at the outset) offered as an option in Los Angeles Department of Transport Go LA app designed by Xerox and in the Dallas Area Rapid Transit trip planning app. These initiatives are analogous to those offered by several commercial third-party routing apps described in Chapter 2 .

Going beyond simply providing an in-app booking option, several initiatives and nascent partnerships have focused on providing discount codes for one-off events or promotions linked to public transport services. In some instances, these discount codes may help compensate for a temporary lack or loss of service. The focus here has often been to get people to start using combined ride-sourcing and public transport trips or to ensure that public transport remains a compelling choice even at times when service is infrequent or after hours. Many of these promotional offers are limited to specific geographic locales and/or times of day - features that are easy to set up within the platform and deliver to consumers in the app. Examples include: 
- In conjunction with the opening of the Los Angeles Metro Expo Line extension, Uber partnered with LA Metro to offer a USD 5 discount off UberPOOL (Uber's commercial ride sharing service) starting or terminating at any new Expo Line Station 20-22 May 2016 (Friday-Sunday).

- In July 2016, in time for several large regional events, San Diego Metropolitan transit operator (MTS) partnered with Uber for a 17-day promotion. Travellers starting or ending trips at participating MTS Trolley or Rapid stations could enter a promotion code to receive USD 5 off an UberPOOL ride.

- During August 2016, Uber put in place the uberTREIN promotion whereby riders received discounted trips to and from the airport while the rail corridor linking Schiphol airport to Amsterdam was undergoing maintenance. Uber fares were capped at the cost of the train ride (EUR 16.80), approximately $30 \%$ lower than the un-capped average Uber fare on the same route.

- On weekends in December 2016, Australia Capital Territory (ACT) Government and Transport Canberra partnered with Uber to ensure late-night, last-mile connections from Night Rider bus stops between 22:00 and 2:00. Using in-app geofencing and a promotion code, riders requested UberX service from within 20 metres of designated Night Rider stops to any location within one of three geographic zones. Qualifying rides received a AUD 10 discount covered half by the ACT Government and half by Uber.

- Starting in 2015, Uber started offering a one-time USD 20 discount for travellers going to or leaving from a MARTA Metro station in Atlanta. Uber has other one-time promotions in Des Moines, Iowa, and Dallas, Texas.

- Uber started a programme in Portland in 2015 where for every first ride a customer took, Uber donated USD 5 to the Westside Transportation Alliance to work on sustainable transport options.

- For a limited time in August-September 2016, Miami-Dade county and Uber experimented with offering UberPOOL rides a flat USD 3 fare for rides connecting to Metrorail stations during Metrorail hours of operation. During the same period, Uber also helped distribute (via their drivers) free pre-loaded EASY public transport passes to encourage riders to try mixing Uber and Metrorail.

- During the closure of the Alaskan Way Viaduct in Seattle in April-May 2016 the Seattle Department of Transport partnered with Uber to offer flat-rate USD 2.50 UberHOP (a route-based ride-sharing service that was the predecessor to UberPOOL) rides between the central business district and South Lake Union as well as to and from a selected group of water taxi stops.

- When the Massachusetts Bay Transportation Authority (MBTA) curtailed late night services on the T line in March, 2016, both Lyft and Uber initiated temporary discounts for night ride services to and from $T$ stations. For several weeks between 00:30 and 4:00, Lyft offered up to a 75\% discount for shared Lyft Line rides along the $T$ line and Uber offered a flat USD 5 UberPOOL fare.

- The town of Evesham, New Jersey, started a unique programme in October 2015 to cover the cost of free rides home with Uber from selected bars, restaurants and other establishments from 21:00 to $02: 00$ in a bid to reduce drink-driving.

In some instances (e.g. Evesham and Seattle), local authorities temporarily helped cover the cost of ride-service trips when they met specific conditions. 


\section{Formal partnerships with public transport involving subsidies and integration}

Many of the promotions described above are time-bound or very limited in their area of application. They represent very early experimentation by companies and public authorities seeking synergies between the types of services provided by ride-sourcing and commercial ride-sharing companies and public transport operators. Many of these initiatives seem to focus more on marketing the notion of combining ride service and public transport trips to the public than on replacing certain public transport services with ride services. They do not represent a structural shift in the way public transport is delivered though they do open a doorway to exploring further, more formal partnerships. This is what has happened in several jurisdictions as described in the following examples.

Altamonte Springs, Florida

In March of 2016, the City of Altamonte Springs, Florida - a low-density city near Orlando - started a pilot programme to subsidise $20 \%$ of the cost of every trip beginning and ending within city limits. In addition, the city subsidises $25 \%$ of the cost of all Uber trips starting or ending at the Altamonte Springs SunRail station. In July, 2016, the pilot was expanded to four neighbouring communities.

\section{Centennial, Colorado}

From August 2016 to February 2017, the City of Centennial ran a six-month pilot programme offering free rides to and from the Dry Creek Light Rail Station within a geofenced area. The Go Centennial pilot temporarily replaced the Dry Creek Call-n-Ride service with a shared Lyft Line or Via Mobility Service (a paratransit service provider) rides. In addition to those ride-service companies, the Go Centennial partnership also included the City of Centennial, $\mathrm{CH} 2 \mathrm{M}$, the Denver South Transportation Management Association (DSTMA)/Southeast Public Improvement Metropolitan District (SPIMD), and Xerox (Conduent). The service was accessed through the Lyft app or through the Xerox-developed Go Denver app as well as through a call response centre supported by Lyft. Available Monday through Friday from 5:30 to 19:00, the pilot sought to increase ridership on the light rail system and decrease car use for accessing the rail station or driving to Denver. The programme is currently (Spring 2017) under evaluation having run its initially planned course.

\section{Dublin, California}

In early 2016, the Livermore Amador Valley Transit Authority (LAVTA) and their transit operator, Wheels, started investigating ways to better serve connections between low-density suburban neighbourhoods and the East Dublin/Pleasanton BART metro station. Bus service was costly in those areas and in August 2016 LAVTA shut down an underperforming bus line ${ }^{1}$ with an eye to replacing it with ride-sourcing and taxis.

In January, 2017, LAVTMA signed agreements with Desoto cab, Lyft and Uber to launch the Go Dublin! Rideshare pilot set to initially run through June, 2017. This pilot offers a $50 \%$ reduction on all Desoto taxi Share, Lyft Line or UberPOOL rides (up to USD 5) taken anywhere within Dublin, including to and from the East Dublin/Pleasanton BART metro station. Lyft, Uber and Desoto all offer booking apps that process credit card payments and Desoto also allows telephone booking and cash payments. Based on average distances and costs, LAVTA estimated its average subsidy coverage required would be USD 5 per trip. Funding for the pilot came equally from Wheels (USD 100 000) and from a grant from the Alameda County Transportation Commission (USD 100 000).

\section{Pinellas County, Florida}

In January 2016, the Pinellas Suncoast Transit Authority (PSTA) expanded a smaller Uber-PSTA pilot programme to the entire county and extended it to other ride services and taxi companies, including 
paratransit operators. The expanded Direct Connect service links locations within the county to designated bus stops. PSTA estimates users will pay USD 1 on average with the authority covering up to USD 5 per ride. The new service covers rides taken with Uber, Lyft, United Taxi, and Care Ride and Wheelchair Transport. The latter two offer specially-equipped paratransit vehicles, the latter three accept telephone reservations and United Taxi accepts cash payments. A special promotion offered free bus rides for those using the service in its opening month. The Direct Connect pilot is slated to run six months and will be re-evaluated. Part of the motivation for the initial pilot was the rejection by local voters of a referendum in 2014 that would have helped to fund an expansion of the county's bus service and build a 24-mile light rail system.

\section{San Clemente, California}

In October, 2016, the Orange County Transportation Authority (OCTA) started a new exclusive partnership with Lyft in low density neighbourhoods previously served by two fixed-service bus routes. The rationale for seeking out this arrangement was the high cost of operating the services for too few riders and to free up these resources for better service and higher frequencies elsewhere in the OCTA network.

Using an in-app promotion code, riders benefit from reduced-price Lyft fares. Depending on distance, riders picked up or dropped off at stops along the old bus route from 6:00 to 20:00 pay USD 2- 5 for rides that otherwise would have cost USD 5- 14 using Lyft's regular pricing. The City of San Clemente subsidises the difference until the approximately USD 100000 budget allocated for this pilot is exhausted. Additional sources of revenue for the programme are being explored by both Lyft and OCTA to extend the pilot's duration. The programme requires using the Lyft app on a smartphone but since not all Orange County residents own a smartphone or have an adequate data plan, City officials will help qualifying residents purchase government subsidised smartphones. In order to monitor the impact of the pilot, Lyft provides monthly ride statistics to OCTA.

Town of Innisfil, Ontario, Canada

The town of Innisfil has entered into a partnership with Uber to provide its 36000 residents guaranteed rates and rides through the Uber app. As part of this partnership, the town will provide CAD 100000 in 2017 and CAD 125000 in 2018. Residents will pay base fees for trips to key locations in Innisfil, and the town will pay Uber the balance. For example, Innisfil residents will pay CAD 3 per person for any trip to or from the Innisfil Recreational Complex and Town Hall area, and the town will cover the remainder of the fare, from CAD 6-9. Residents will also be able to book a trip from Innisfil to anywhere they wish and receive CAD 5 off their fare.

City of Summit, New Jersey

The City of Summit Commuter Ridesharing Pilot Program, a six-month pilot started in October 2016, covers the full cost of Uber rides to or from the Summit light rail station (in fact, to and from a specified pick-up and drop-off zone adjacent to the rail station) for Summit residents who have paid their monthly parking pass at the rail station. This is because the programme aims to reduce the number of commuter cars left in parking lots during workdays. The pilot is limited to 100 participants who are either parking pass subscribers or non-parking pass subscribers. Parking pass subscribers receive free trips to and from the station and non-parking pass subscribers will be charged a flat USD 2 rate per ride. Because the focus is on work commute trips, rides are limited to two per workday per person and from only 5:00 to 21:00.

Partnerships to provide paratransit services: Massachusetts Bay Transportation Authority

The Massachusetts Bay Transportation Authority (MBTA) has partnered with both Lyft and Uber to offer subsidised paratransit trips via each ride service company's platform during a year-long pilot starting in 
September 2016. Registered users of MBTA's THE RIDE paratransit service will now be able to book on-demand service via their smartphone instead of having to call in advanced reservations. Phone booking is also offered for Lyft rides via their call-in centre and Uber is making available a limited number of smartphones for qualifying riders. Riders will pay the first USD 2 of the trip with MBTA covering up to USD 13 extra; although riders must cover any remaining trip costs, MBTA believes the majority of trips will fall within the USD 15 overall rider plus subsidy cost. This compares to rider costs of USD 3.15-5.25 for RIDE trips before the pilot and an average trip cost of USD 31. The pilot will offer instantaneous booking and low wait times in contrast with minimum one-day advance reservation and one half hour pick-up windows. The service covers the greater Boston area with the exception of Logan Airport. Both ride service companies offer wheelchair equipped vehicles, Uber through its UberACCESS programme and Lyft through a partnership to provide Lyft drivers with wheelchair-accessible rentals. MBTA offers an additional USD 12 per completed trip to Lyft drivers renting wheelchair-accessible vehicles. Finally, both Uber and Lyft will provide free training to RIDE pilot drivers to help mobility or otherwise impaired customers get into and out of their vehicles.

\section{Other initiatives}

\section{Platform-based microtransit: Kutsuplus, Helsinki}

Kutsuplus was a three-year trial of a pop-up bus service offered by HSL, the Helsinki-Area public transport operator. Based on app-ordered minibus services that optimised routes in real-time, the service promised flexible, on-demand microtransit in central Helsinki at an attractive price for riders. Trips cost a base fee of EUR 1.50 plus an additional EUR 0.15 per direct-route kilometre (due to the nature of the service, actual service deviated from the direct route due to additional pick-ups and drop-offs). The project was the first of its kind bringing together microtransit and an app-enabled on-demand booking/payment environment but ultimately was not renewed in 2016 due to uneconomic performance linked to two design flaws. The first was that too few vehicles were deployed and the second was that the trial area was too large. Together, this meant that wait times were unacceptably long and the service never gained commercial traction (HSL, 2016). The dispatching algorithm and the app itself were seen as innovative and valuable and the IT-company behind both is still involved in other ride-service initiatives.

\section{Platform-based microtransit: RideKC Bridj, Kansas City}

Bridj was a platform and app-based microtransit service that offered on-demand micro-bus services within and between set zones. Users requested service via the app and were directed to a pop-up stop where the bus picked them up. The service offered guaranteed seats, free Wi-Fi, no transfers and fewer stops along the way. The flexibility of Bridj's platform, in use in Boston and at least briefly in Washington, DC, led Kansas City, Missouri, to develop a pilot program around it to offer new commuter services between areas of the city that had been difficult to service with traditional buses. The exact service boundaries are flexible and Bridj's platform allows for real-time adjustments to meet where people are requesting rides.

The RideKC pilot ran from March 2016 to March 2017 and built on a partnership between the Kansas City Area Transportation Authority (KCATA), Ford Motor Company (for the American Disabilities Act-compliant mini-buses) and Bridj for the app-based ride matching platform. The drivers were KCATA drivers that had volunteered to participate in the pilot. The service was offered during the morning and evening peak commute periods and cost riders USD 1.50 per ride (with the first 10 rides free). The remaining costs were covered by KCATA who spent USD 1.3 million on the pilot programme.

In the end, the pilot was not extended as it had only generated 1480 rides over the course of the year - an extremely small uptake in a city of more than 2 million people. There were numerous reasons for the pilot's poor performance. Too few people knew about the service - approximately $40 \%$ of the people in the pilot 
service areas had not even heard of the service. Rider retention also posed challenges - nearly half of all riders only made one trip with the service and only $9 \%$ of all riders made 10 trips or more. Reasons for this low retention rate included the fact that services didn't go where riders wanted to travel or at the times they wanted to travel (especially late at night). Riders noted that the service was attractive because it was less expensive than alternatives. Survey evidence six months into the pilot found that riders used the service instead of a car trip $(\sim 30 \%)$, a bus trip ( $\sim 30 \%)$ or a ride service (in this case, Uber $-\sim 22 \%$ ) (Marshall, 2017; Shaheen et al., 2016c). KCATA plans to use the lessons learned in the pilot to deploy an app-enabled service targeting riders in need of accessible paratransit services at subsidised fares but open to all potential riders without fare support.

Bridj itself ceased operations in April, 2017 after three years of operations as a result of a cash shortfall that resulted when the company was unsuccessful in attracting new capital. Following on the demise of Kutsuplus, the closure of Bridj, which had been highlighted as one of the more innovative start-ups in the ride-service and public transport field, underscores the difficulty that app-enabled on-demand micro-bus shared ride services face at present. Whether the difficulty rests in service design, poor implementation, context-specific challenges or fundamental challenges related to this type of ride service model remains to be seen.

Real-estate developer incentive to use ride services with public transport

Developers often face costs associated with providing a legally mandated minimum number of parking spaces for their properties. It is in their interest therefore to reduce those costs but they will only do so if inhabitants or tenants have sufficient alternatives to car use such that the commercial value of the real estate does not suffer in the absence of sufficient parking. Maximus Real Estate Partners, the developer of ParkMerced in San Francisco, is experimenting with offering residents a USD 100 per month stipend to cover multimodal transport, including Uber and public transit. The stated goal of the initiative is to make car-free living as easy and convenient as possible. Uber is partnering with ParkMerced by capping uberPOOL fares to and from nearby the Daly City BART, Balboa Park BART, and Westportal MUNI public transport stations at USD 5.

\section{Features of current ride service: Public transport partnerships}

Though the previous examples show a great diversity in the types of services being offered and the range of partners involved, there are a few key characteristics emerging from the admittedly restricted set of mostly North American initiatives. The first is that there are a great number of temporary, one-time promotions being trialled by both commercial ride service companies and local authorities. These seem largely to either serve a particular need for extra capacity due to disruptions to public transport systems (e.g. in Seattle and in Amsterdam) or as a way to help travellers learn new behaviours combining ride services and public transport. These are interesting in that they allow a lot of creative trialling of services but unless they are extended and incorporated into a more formal partnership, they are unlikely to durably impact behaviour.

Most of the more extended formal partnerships between ride services and public transport, with the exception of the Boston MBTA's RIDE paratransit service (and similar initiatives planned in New York City and Washington DC), have occurred in smaller, low-density, suburban towns. This is understandable given the elevated cost of providing fixed bus service in these geographic contexts and also because of the simplicity of organisation and governance at that scale. Because of this, these geographic contexts are where these services may naturally develop and possibly be confined. However, ITF analysis from previous Corporate Partnership Board reports indicate that exclusive deployment of shared mobility systems has potential to handle all trips across entire urban regions with significant benefits (ITF, 2016c). If this were to be the case, then the nature of these early pilots, and the regulatory frameworks surrounding their 
deployment, will have to adapt to situations where they potentially play a greater and greater role in everyday mobility across wider urban regions.

All of the initiatives currently underway are organised as pilot programmes. This is to enable learning from the exercises and to mitigate some of the potential risk if the pilot does not perform as expected and hoped. Pilots allow a safe, time-bound, space for experimentation and ensure that ex-post evaluation occurs before the initiative is prolonged, adapted or terminated. Perhaps one of the most compelling reasons, however, that these initiatives are run as pilots is that they allow public authorities to enter into contractual agreements with service providers without going through typical procurement processes. This is due to the limited budget involved which in most instances is below the threshold for formal bid processes and due to the temporary nature of the partnerships. In some instances, however (the RIDE partnership in Boston), the pilot is run through a bid-based procurement process. Another aspect of some pilots is that they are open in that any provider meeting the criteria can participate (up to the exhaustion of the allocated budget if a subsidy is involved). This also allows authorities to test new service configurations without going through a formal procurement of exclusive services.

Finally, it is worth noting that the pilots described in this section are embedded in a US-specific public transport agency context where funding is generally lacking, where political support for public transport and trials are sometimes mixed and where agencies are burdened with constraining procurement processes and are generally risk averse.

US Federal Transit Agency guidance on shared mobility and public transport

Since many of these experiments are taking place in the United States, the Federal Transit Agency (FTA) has issued guidance to local authorities to help them design ride service - public transport partnerships. Issued on 30 January $2017^{2}$, this guidance takes the form of several frequently asked questions (FAQs) seeking to clarify requirements for shared mobility alternatives regarding funding eligibility under federal public transportation law for FTA grant programs and compliance with federal requirements, such as the Americans with Disabilities Act (ADA).

The FTA defines public transport as "regular, continuing shared-ride surface transportation services that are open to the general public or a segment of the general public defined by age, disability or low-income" (FTA, 2017), and finds that ride services may qualify for funding depending on the nature of the service provided. In particular, FTA makes the distinction between "shared-ride" service and "exclusive ride" service. The former are services where open sharing of the ride occurs by design and passengers or drivers cannot limit who comes on board if there is capacity, conditioned on certain operational, safety or security considerations. Ride services which can be reserved for the exclusive use of individuals or private groups, either by the operator or the first passenger's refusal to permit additional passengers, are considered exclusive-ride services (FTA, 2017). Generally, exclusive ride services are not eligible for funding through Federal grant programmes (with some limited exceptions where the exclusive ride service is part of a specific programme supporting alternatives to public transport - like some job access programmes).

Both operational and capital expenditures are allowed for shared ride services. The former may involve infrastructure modifications for pick-up and drop-off zones and the latter may involve reimbursing a public transport operator or a public agency for the costs associated with subsidising first and last-mile access to a public transport network using ride services. FTA rules, however, prohibit the direct payment to ride service companies.

The January 2017 guidance also helps US authorities determine how to reconcile Federal requirements regarding access for the disabled enacted in the American with Disabilities Act (ADA) and ride service partnerships. Generally, all fixed-route public transport services must be provided with ADA-compliant vehicles whereas all non-fixed route services must themselves be ADA-compliant. This distinction means 
that a ride service based on fixed routes must employ vehicles that enable, for example, wheelchair access. On-demand services, on the other-hand, must allow convenient, affordable and timely access to wheelchair-accessible vehicles though not all vehicles deployed in the service must meet these criteria as long as the vehicles have a capacity of less than 16 people including the driver.

For instance, the services operated by Chariot, described in Chapter 2, use vehicles with a capacity of less than 16 people and thus the rules state "the vehicles must be accessible unless the fixed route system, when viewed in its entirety, provides equivalent service to persons with disabilities, including wheelchair users" (FTA, 2017). In the case of the KACTA-Bridj trial, vehicles were ADA-compliant whereas Bridj's Boston service and Chariot's services, the overall service, but not necessarily every vehicle, provide "ADA equivalent" service. In this context, the service design and the involvement of partners with sufficiently large fleets of wheelchair-accessible services, can ensure conformity with ADA requirements. Arguably, the flexibility and effectiveness of platform-based ride sourcing allows better deployment and use of the accessible fleet as compared to single operator paratransit services. Platform-mediated ADA vehicle requests also enable the pooling of adapted vehicles across multiple suppliers. The potential increase in efficiency and improvement in wait times and other outcomes are what motivated MBTA to pilot its RIDE service with Lyft and Uber in the first place. 


\section{Framing the convergence of ride services and public transport}

\section{From public transport to a "Mobility as a Service" ecosystem}

Public policy is best served when it is framed within a coherent set of visions and goals. This ensures that specific initiatives, measures and partnerships contribute to shared and clearly articulated outcomes. This is especially important in complex situations where there is a risk that uncoordinated policies may serve counter-purposes or even may erode generally shared but poorly articulated objectives. A commonly-referenced framework vision also helps ensure consistency and complementarity in investment and planning decisions that may span decades. Because it is complex and subject to so many influences, urban transport policy is one area where these risks are elevated and the need for correctly framing policy is clear.

Many urban regions, especially in Europe, have a long tradition of carrying out co-ordinated urban mobility plans that frame transport decision-making and investment. In France, Germany and certain other countries, these plans are required by national law; they must conform to specific methodologies and the outcome of the plans are linked to legally enforceable decisions. Outside of Europe, India and Brazil have put in place national requirements for urban mobility planning though their implementation remains challenging. Many urban regions also create long-term strategic plans in order to help guide transport and land-use policy and, in some cases, as in regional metropolitan planning organizations in the United States, to help meet requirements in order to gain access to national funding sources.

These plans require a lot of input, and may be time-consuming to develop but once completed, serve as a common reference until they are updated or replaced. There is a risk in this context that these plans may not adequately address fast-changing circumstances and emerging phenomena. This seems to be the case with the treatment of innovative mobility services, the potential impact of automated driving and how digitally-driven changes may fundamentally challenge the concept of public transport. Plans that address these issues and provide guidance in dealing with uncertainty regarding the way in which urban transport ecosystems will evolve can frame policy addressing the evolution of public transport. The city of Los Angeles' Urban Mobility Plan in a Digital Age, for example, illustrates one such comprehensive and future-proof vision-setting exercise (see Box 3). Another good example is Finland's Strategic Growth Environment Plan For Digital Transport that also addresses multimodal regulatory and market access issues, and data accessibility; it paves the way to automation and nationwide Mobility as a Service platform.

The convergence of public transport and emerging mobility services opens up innovative mobility options for many people. The upside potential of this convergence is difficult to realise under traditional public transport service delivery models. This is because that potential rests on leveraging synergies between legacy systems and emerging technologies, between operators that may display considerable institutional inertia and more agile new players and because the very service being "produced" by public transport operators may no longer represent the best option for delivering satisfactory outcomes to travellers in certain circumstances.

At the very top level, reforming governance structures for transport services should as much as possible seek to gather responsibility for all aspects of transport service provision under one coherent framework. This may be a specific agency or an oversight committee that sets objectives and policies, in some cases carries out operations or licensing/contracting, monitors outcomes and follows up with adjustments as necessary. 
One of the first challenges facing authorities will be to re-evaluate what constitutes public transport, what outcomes authorities should work towards and how to ensure that these outcomes are aligned with what people want. Equitable access will be part of the equation, as will efficiency improvements that deliver cost savings - but the fundamental building blocks of this vision should be structured around the provision of a compelling user experience irrespective of service delivery mode or operator. Initiatives to facilitate mode-agnostic Mobility as a Service ecosystems will be important and will require re-visiting and possibly adapting many of the rules and governance structures that frame urban transport policy.

\section{Box 3. Los Angeles' vision for a digitally-enabled transport system}

Urban Mobility in a Digital Age is a transportation technology strategy that is meant to guide the City of Los Angeles and its Department of Transportation (LADOT) as regulator and transportation service provider in a complex and evolving ecosystem of public and private services. It focuses on building a solid data foundation, leveraging technology and design for a better customer experience, creating partnerships for more complimentary shared services, establishing feedback loops for services and infrastructure, and preparing for an automated future. Urban Mobility for a Digital Age seeks to position LADOT as a platform for mobility innovation that supports better transport options by targeting three impact goals:

Goal 1: Data as a Service

LADOT must be able to provide and receive real-time data from an increasingly complex marketplace of public and private transportation service providers, other jurisdictions, and connected and automated vehicles to maximise the efficiency and safety of the road and transportation networks. This requires a seamless data exchange with a variety of partners and stakeholders, privacy and security protections, the capacity to analyse data from a variety of resources, and the ability to integrate this insight into a data-driven decision-making process at the level of elected officials and department management.

Goal 2: Mobility as a Service

Mobility as a Service seeks to develop a single platform and payment system that offers access to a suite of transportation mode choices, often bundled together in packages in order to improve transport outcomes for people. LADOT has already partnered to make it easier for customers to evaluate transportation options through a trip planning application, Go LA, which compares mode options for the fastest, cheapest and/or greenest routes. Additionally, LADOT has piloted a mobile payment application for its transit services and there are plans to expand Go LA to include reservation and payment capabilities in Summer 2016. LADOT is committed to being a leading advocate for expanded access through a series of actions to better connect and integrate the existing marketplace of public and private services.

Goal 3: Infrastructure as a Service

Infrastructure as a Service proposes that the use of public infrastructure should be subject to pay-as-you-go user fees that more closely align the costs associated with providing the infrastructure itself to how the infrastructure is being used. Infrastructure as a Service more transparently reflects the costs to build, maintain and operate public infrastructure by charging fees for this service. With a solid data baseline, this approach can also support tiered fees to ensure there is equity in access to the public right-of-way. Infrastructure as a Service can help shift behaviour by incentivising shared mobility, promoting staggered commute times and other active transportation alternatives.

Source: Adapted from LADOT (2016).

\section{Comparing mobility services and public transport}

The innovative mobility services outlined in Chapter 2 help people travel without needing to own a car. As with good quality public transport, these services help make it as easy to live without a car as with one and in some cases, more easily. While a car-free city may not be possible or even desirable in many areas, the wide palette of newly available mobility options allows metropolitan areas to flourish even as they mitigate the negative impacts of exclusive, and possibly excessive, car use. And while public transport also contributes to this goal, it displays several characteristics that differentiate it from emerging mobility 
services. Table 1 highlights many of the main differences between the two (the author of the source recognises some over-generalisation).

Table 1. Characteristics of public transport and emerging mobility services

\begin{tabular}{|c|c|c|}
\hline & Public transport & Emerging mobility services \\
\hline Modes & $\begin{array}{l}\text { Bus } \\
\text { Rail } \\
\text { Ferries } \\
\text { Paratransit }\end{array}$ & $\begin{array}{l}\text { Ride-sourcing, commercial ride-sharing } \\
\text { App-based microtransit } \\
\text { Car-share } \\
\text { Bicycle-share }\end{array}$ \\
\hline Service design & $\begin{array}{l}\text { One size fits all: } \\
\text { - } \quad \text { Spread over service area } \\
\text { - } \quad \text { Typically constrained by } \\
\quad \text { administrative boundaries } \\
\text { - } \quad \begin{array}{l}\text { Partial focus on basic access and } \\
\text { public service obligations }\end{array}\end{array}$ & $\begin{array}{l}\text { Differentiated by: } \\
\text { - } \quad \text { Quality } \\
\text { - } \quad \text { Price } \\
\text { - } \quad \text { Shared/exclusive } \\
\text { - } \quad \text { Convenience }\end{array}$ \\
\hline Service delivery & $\begin{array}{l}\text { Scheduled } \\
\text { Network-based mass movement of people } \\
\text { (especially for rail-based systems and Bus } \\
\text { Rapid Transit) } \\
\text { Feeder services to core networks } \\
\text { More diffuse bus-based networks } \\
\text { Route and station/stop-based }\end{array}$ & $\begin{array}{l}\text { On-demand } \\
\text { Mix of: } \\
\text { - } \quad \text { Diffuse, point-to-point or } \\
\text { door-to-door services } \\
\text { - } \quad \text { Station-based vehicle pick-up and } \\
\text { drop-off } \\
\text { - } \quad \text { Non-hierarchical networks }\end{array}$ \\
\hline Planning process & $\begin{array}{l}\text { Often uncoordinated decisions: } \\
\text { - } \quad \text { Mode, fares, service area } \\
\text { - } \quad \text { Service coverage } \\
\text { Service becomes sum of these } \\
\text { decisions }\end{array}$ & $\begin{array}{l}\text { End-to-end customer experience: } \\
\text { - } \quad \text { Ease-of-use } \\
\text { - } \quad \text { Reliability } \\
\text { - } \quad \text { Consistency } \\
\text { Transparency }\end{array}$ \\
\hline Regulation & $\begin{array}{l}\text { Generally mode-specific, } \\
\text { Regulation in return for delivering } \\
\text { minimum coverage for unprofitable } \\
\text { services }\end{array}$ & $\begin{array}{l}\text { Operational licensing } \\
\text { Driver vetting } \\
\text { Safety } \\
\text { Access to public right-of-way and } \\
\text { infrastructure }\end{array}$ \\
\hline Vehicles & $\begin{array}{l}\text { High-capacity buses and trains } \\
\text { Paratransit vans }\end{array}$ & $\begin{array}{l}\text { Diversified: } \\
\text { - } \quad \text { Seating capacity } \\
\text { - } \quad \text { Basic or luxury }\end{array}$ \\
\hline IT technology & $\begin{array}{l}\text { Overlaid onto existing systems } \\
\text { (Generally) data-poor }\end{array}$ & $\begin{array}{l}\text { Integral to operations and customer } \\
\text { interface } \\
\text { Data-rich }\end{array}$ \\
\hline Workforce & $\begin{array}{l}\text { Full-time } \\
\text { Often unionised }\end{array}$ & $\begin{array}{l}\text { Mix of full-time and part-time } \\
\text { Independent contractors and non-union } \\
\text { employees } \\
\text { Various levels of professional competence }\end{array}$ \\
\hline Fares and prices & $\begin{array}{l}\text { Fixed fares } \\
\text { Low fares and social pricing models } \\
\text { Bundled subscriptions }\end{array}$ & $\begin{array}{l}\text { Distance and time-based prices } \\
\text { Variable pricing to modulate demand and } \\
\text { manage capacity } \\
\text { Some fixed prices and subscriptions }\end{array}$ \\
\hline Focus of funding & Large-scale marquee projects & Maximise growth and market share \\
\hline
\end{tabular}

Source: Based on Schaller (2016b).

Perhaps the most fundamental difference between public transport and the business models of many emerging mobility providers is that the provision of public transport is almost always seen as necessary to provide a minimal level of service to a portion of the population. At the same time, where markets are sufficiently dense and the context supports it, high-quality public transport is also perhaps the only way to provide access-improving mobility efficiently and affordably. For both of these reasons, public authorities strictly regulate public transport while, at the same time, accept paying for the broader services it provides beyond what is covered by farebox revenues. Public authorities consider these payments necessary in order 
to sustain minimum service coverage, to keep fares affordable for those that depend on public transport and because they consider that public transport delivers external benefits.

This is a quite different approach from the way that many emerging mobility services have been treated in public discourse and in policy-making. Initially, few authorities saw these services as threatening public transport and its various missions. However, as taxi markets are increasingly disrupted by ride service companies, there is an increasing realisation that public transport may be next and that authorities must re-evaluate their stance on the whole mobility ecosystem in a unified and coherent manner. There are many reasons that this will not necessarily be straightforward, not least of which is that some see emerging mobility services, and ride services in particular, as increasingly competing in the same space as public transport (and potentially for certain pedestrian and cycling trips).

\section{Managing competition between innovative mobility services and traditional public transport}

A recurrent fear raised in discussions surrounding the convergence of public transport and ride services is that the latter will cannibalise the former, drawing away riders (especially "premium" riders) and revenues, and ultimately eroding the capability for public transport to provide quality services and contribute to equitable outcomes. This, if true, would certainly counter stated policy objectives for many public authorities and would require strong action to prevent such a loss. This framing of the question - ride services and public transport competing for a uniform, fixed and possibly even shrinking market, however, belies the reality in many cities.

In low-density and thin bus markets, many public transport operators are struggling to offer services that are competitive with car use. In those areas, those who can afford cars, who find them a more convenient option to low-frequency, inflexible bus services and who can safely operate them have already largely abandoned bus services - even if these services may feed into higher frequency and better quality public transport networks. Those bus users who remain are often captive users who have few alternatives.

As noted earlier, not all trips are the same and many are quite expensive to supply via traditional, often bus-based, services. In these contexts, ride services can be (and have been) seen as a way to deliver the same trips as those delivered by some bus services but at lower overall costs. This motivation - to use ride services as a way to reduce public transport operating costs and subsidies in thin markets - seems largely to have been the motivation for several recent trials like those described in the previous chapter. It is important to note, however, that these cost savings are driven by the shift to more variable cost factors, including labour, which can be directly matched with any revenue gained from operations. Ride service models clearly leverage capital cost savings from switching from large public transport vehicles sized for peak demand to smaller vehicles that can more flexibly handle most demand. Ride services also benefit from lower variable costs savings related to lower labour-related costs. These result from most ride services employing a business model that depends on using independent, oftentimes less trained and sometimes less skilled drivers in place of full-time, generally more skilled and organised labour. With the collective bargaining power of the latter also comes defined benefits, including pensions, that independent contractors lack. There are exceptions to this rule, for example KCATA's use of the agency's unionised bus drivers for the Bridj pilot described in the previous section.

Cost savings are therefore an important motivation for seeking to replace certain expensive public transport routes with ride services. They are also an important motivator for early action as they provide a tangible reason to act. But going forward, it is not clear that cost savings are either a sufficient motivation or even a major motivation for seeking better synergies between ride services and public transport - at least where there is a desire to improve mobility and access outcomes for as broad a group as possible. That is because these synergies, if well managed, can be leveraged to provide improved outcomes for travellers while at the 
same time allowing public authorities to deliver on important public policy objectives such as improved equity, reduced congestion and improved environmental outcomes.

One key factor to consider is that replacing more expensive, less demand-responsive and less flexible public transport services with less expensive, more demand-responsive and more flexible ride services or other combinations of innovative mobility services can free funds that public transport operators could allocate to improving the quality of core services. Under this framing of the question, the potential for ride services and other innovative mobility options to draw away riders from specific routes does not necessarily imply that overall ridership would drop. In fact, if core services are improved and the convenience of using public transport as part of a trip chain increases, then overall ridership may even increase. In the broader picture, adding a more convenient mobility choice into the mix may improve overall access and mobility outcomes even as it reduces the need to own a car.

A recent survey of the trip behaviour of users of ride-sourcing and other emerging mobility services in the United States indicates that this potential is real though the extent of this synergy - especially if ride services significantly increase their overall mode share - is uncertain. According to (Feigan and Murphy, 2016), those who use emerging mobility services - and especially those who use many of these services in conjunction with each other - are likely to be heavy users of public transport as well. This is partly a result of lower car ownership amongst this subset of the population. The survey also found that use of innovative mobility services often complements public transport use (see Figure 4) - but that at certain times of the day and for certain trips, these modes compete for the same riders. Ride services are most used for non-work trips, especially recreational trips, and off-peak hours - especially at night. These are precisely the types of trips that public transport operators find impossible to provide or that are extremely costly to do so. Public subsidies to operators disproportionately cover these low frequency services in thin markets. Replacing these trips with less costly and possibly more convenient options could also free up public resources for other uses.

In other related studies, Feigan and Murphy (2016) found that bicycle-sharing in the United States often serves to access or to extend public transport trips and that car sharing typically occurs in off-peak hours for non-work trips. According to the survey, car-sharing and ride-services were generally seen as competing more with taxi and private car use than with public transport.

There is admittedly insufficient empirical evidence on the impact of ride services and other innovative mobility options on public transport ridership, especially outside of North America. Even if there were, it would be difficult to generalise at this stage on how this impact, either positive or negative, might evolve as more and more people use ride services. But at present, there seems to be evidence that in certain contexts - especially where the provision of public transport services is expensive and quality is low well-targeted policy to replace certain poorly-performing and expensive bus services may indeed increase the overall attractiveness of public transport. In these cases, public authorities and public transport operators can start to evaluate where these synergies are strongest by undertaking inventories of existing public transport routes and services to evaluate the potential for alternative service delivery models including those based on co-operation with ride services. These inventories would be best served by seeking improvements in overall outcomes rather than only looking solely at cost savings.

Further evidence-based analysis of the interaction effects between ride services and public transport, and the overall impact on mobility outcomes can also help guide policy-making in this area. This will require perhaps more information from rides services than they have typically provided in the past (we discuss data and performance indicator frameworks later) but can lead to better framed policy discussions. 
Figure 4. Uber pick-ups and drop-offs (blue) within a quarter mile of suburban rail services (black) in Portland, Oregon

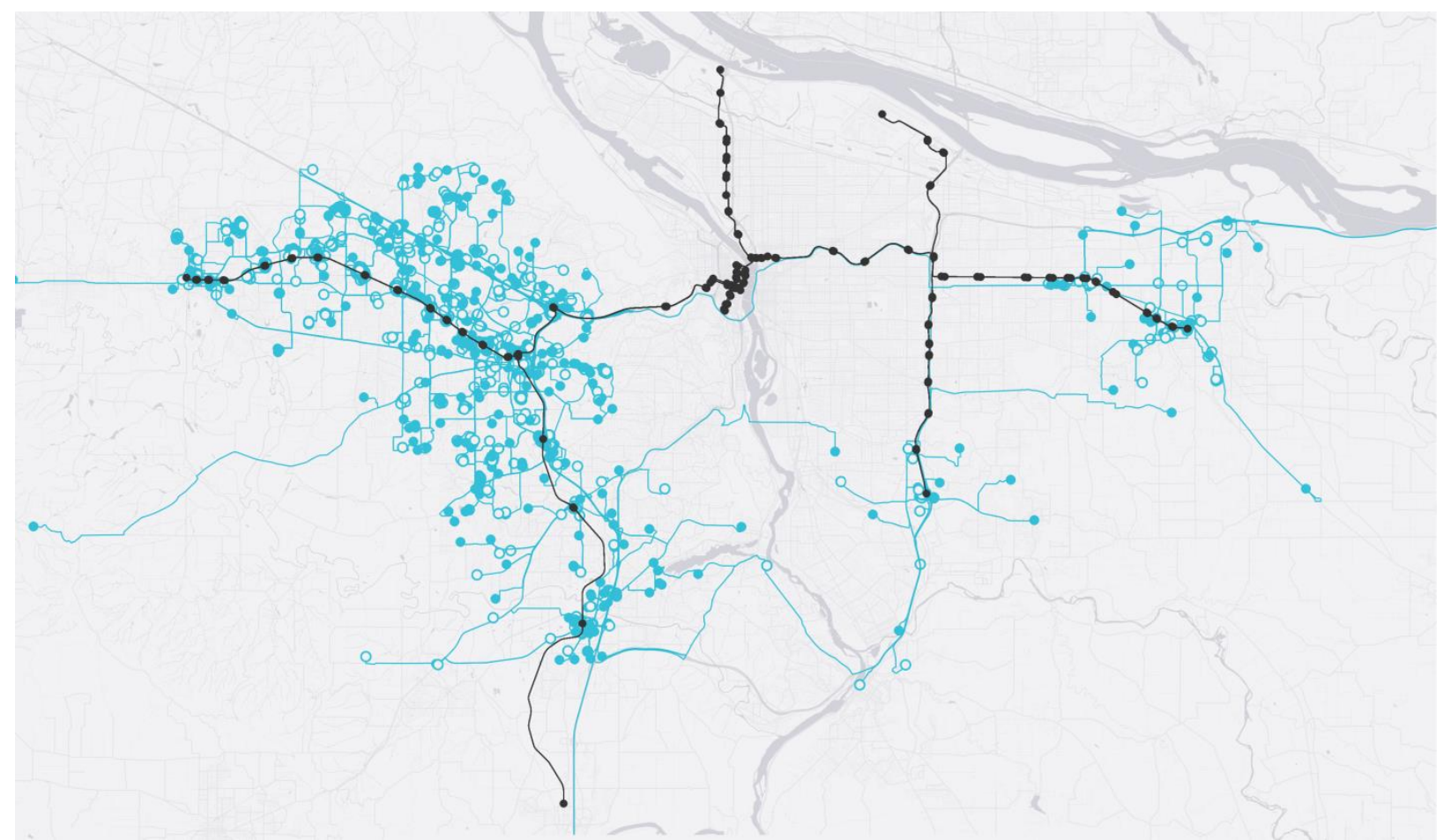

Source: Uber (2017).

The investigation of employee shuttle services between San Francisco and Silicon Valley is one example of this type of evidence-based investigation of the impacts of innovative mobility services. Prior to 2014, a number of bus and mini-bus based employee shuttles proliferated throughout the city bringing workers in the tech industry from their residences in San Francisco to their places of employment in Silicon Valley. Individual companies organised entire networks of routes and stops using public street infrastructure, including marked loading areas and public transport stops, and thus offered a "shadow" public transport network that rivalled that of established services (see Figure 5). These private shuttles were controversial in that boarding and off-loading hampered public bus service and disrupted traffic due to inconsistent enforcement and confusing rules, or the lack thereof. Many felt that these shuttles not only drew riders away from existing public transport services eroding their revenue base but that the shuttles also prioritised the travel of relatively better-paid tech workers over more captive users of traditional public transport.

Starting in January 2014, the San Francisco Municipal Transportation Agency (SFMTA) initiated a pilot program that streamlined and enforced rules and monitored performance in co-operation with shuttle operators. The programme found that while $29 \%$ of the shuttle riders would otherwise have used public transport to get to work, nearly half (47\%) would have driven alone to work along an already very congested route. While the employee shuttle fleet did draw some riders away from public transport, it drew many more people out of cars and thus had a positive impact on peak hour traffic. This analysis led SFMTA to recommend that the shuttles be allowed to operate albeit under tighter regulatory control to ensure as little impact as possible on public bus services in San Francisco (SFMTA, 2015). Such an open-ended, flexible and evidence-based trialling of new rules could also be a model for authorities seeking synergies between ride services and public transport. 
Figure 5. Private shuttle lines between San Francisco and Silicon Valley (2012)

Source: Stamen Design (2015).

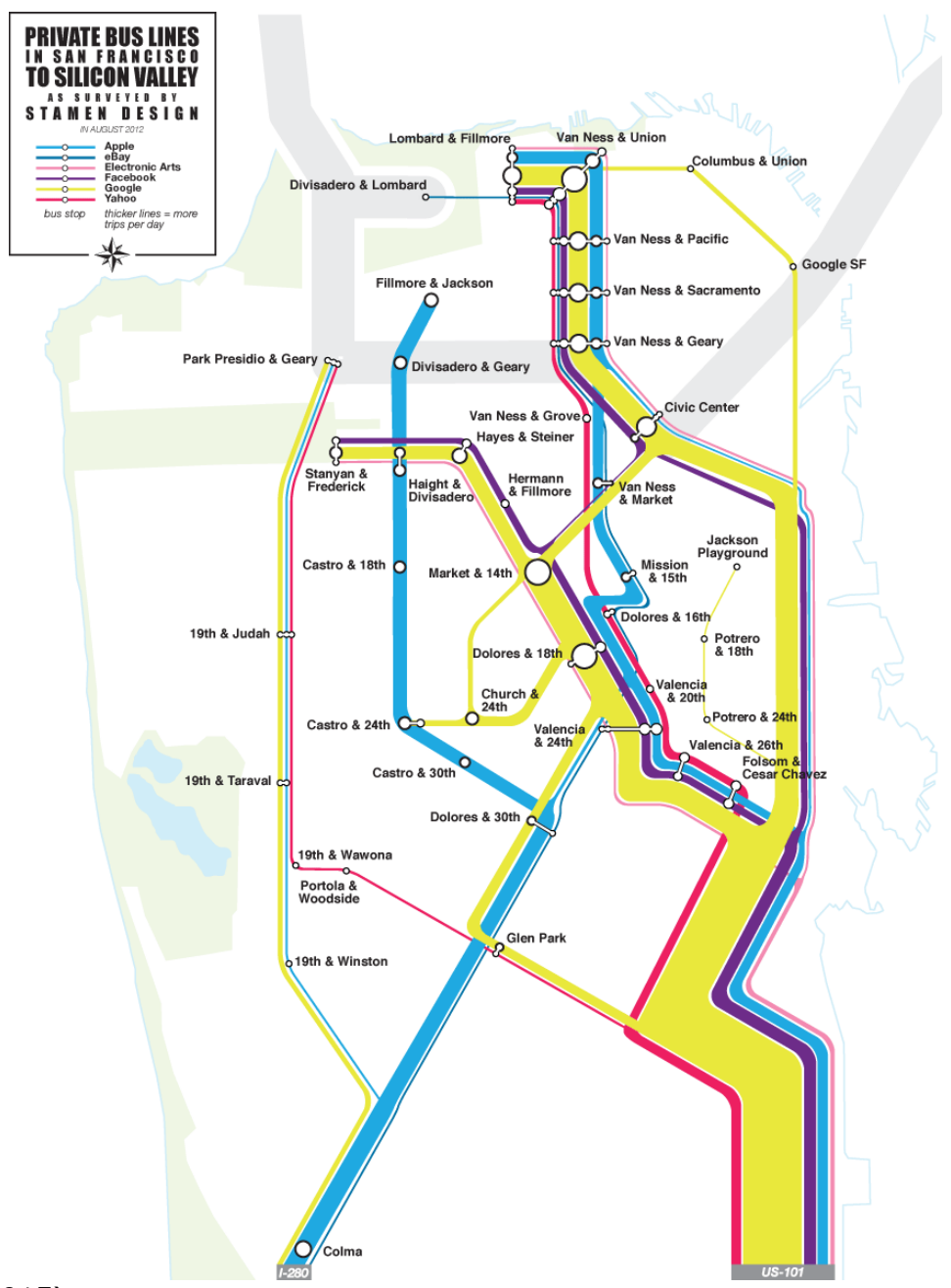

\section{Adopting governance structures aligned with the range of mobility services on offer}

The governance of public transport, and of transport services more generally, will play an essential role in either facilitating or impeding the convergence of traditional and innovative mobility services - and of ride services in particular. In the first instance, the licensing of innovative mobility services and their regulation is a role conferred to governments. These roles may be unified within one level of government or agency but in many instances it may be spread across several levels (national, regional or local). Even at any given level, responsibility may be spread across several departments or services with little top-level co-ordination. This complicates the task of aligning outcomes in, say, the regulation of ride services that may fall under those in charge of taxi or for-hire regulations and public transport regulation which may fall under a completely different authority.

Secondly, initiating outreach to ride services typically comes from public authorities or public transport operators and in many instances, this may be stymied by internal resistance to what may be perceived as direct or unfair competition with public transport services. It may also be difficult since, under the current framework of public transport provision, the less regulated ride service sector may be seen as running 
counter to the public service component of existing services. If transport governance structures contribute to this friction, it may be very difficult to even broach the subject of synergies between ride services and public transport, let alone experiment with them. This is certainly the case where, for any number of reasons, new ride services are prevented from operating or face constraining conditions. At a very basic level, split responsibility and split levels of decision-making may hamper the trialling of innovative new arrangements.

There is a great diversity of governance structures for public transport around the world and the enactment of this governance rests on a wide variety of legal arrangements. These may include authorisations, licences, concessions, contracts or hybrid arrangements built on multiple instruments. Because of this diversity, it is hard to generalise on what seems to be the most effective form of transport governance, especially since this diversity generally rests on local or regional characteristics. Nonetheless, there are three broad service delivery models around the world that necessitate slightly different governance structures.

The first model is characterised by a privatised public transport operator that has significant freedom to make operational decisions and strategic investments. These operators may be fully privatised, as in the case of the Tokyu Corporation providing metropolitan rail services in the Tokyo region, or may consist of operators established as private companies with public shareholders, as in the case of the Mass Transit Railway (MTR) Corporation that operates rail and bus services in Hong Kong. These types of arrangements have led to a certain degree of innovation with regards to funding models that generate revenue from commercial services and real estate linked to public transport networks. Such operators have a strong focus on the profitability of their services and have extremely limited recourse to public subsidies. Because they run generally profit-clearing services, the cost-savings attraction of partnering with innovative mobility services may not be very compelling. But there is room for seeking out partnerships to improve certain operational aspects of services - especially if they attract riders out of congested networks at peak times.

A second, relatively widespread model, for the organisation of public transport is one where the operator is fully under the direct control of a government body and indeed may even be a government agency. Self-provided services are common feature in North America and, to a lower extent, elsewhere. These types of operators have generally emerged from the privatisation of commercial operators when these lost market share in the face of rising car use.

The rationale for bringing public transport under direct government control was to ensure the provision of minimum levels of service, coverage and controlled fares as a safety net to ensure mobility for those unable or unwilling to use cars. These types of operators are governed directly by regional/local transport authorities who define the level of service, fares and coverage. In some instances, national authorities also set requirements for these operators, especially in return for payments and subsidies.

In the United States, government agencies and operators delivering public transport services have been among the first to seek out partnerships with ride services and other innovative mobility operators as outlined in Chapter 3. However, this model may harbour some inherent tensions in that officially partnering with innovative mobility operators, especially those that have limited or no public service obligations, may be seen as running counter to the agency mission. This is one of the reasons the US Federal Transit Administration has issued guidance on the matter. Because of this inherent tension, the scalability of public-private partnerships bringing together public transport with other mobility services may be compromised beyond a limited set of innovators and small- to medium-sized pilot programmes.

A third common model, especially prevalent in Europe (but not exclusively: Los Angeles and Portland are North American examples) is one where transport authorities define the strategic and tactical objectives for public transport but the actual operation of these services is contracted out to independent operators. As described by the UITP, "Organising Authorities are organisations which act in the public interest to ensure a 
well-functioning, attractive, and integrated transport system. They provide the framework for successful public transport directed at economic, social, and environmental value for citizens and business" (UITP, 2009). Conceptually, this model provides greater flexibility for integrating new types of services into the urban mobility mix. FlexDanmark's Flex Traffic platform is one example of this type of approach for integrating on-demand services (see Box 1).

In Europe, this model typically revolves around a competent authority at a regional or metropolitan level that establishes public service contracts with operators to carry out transport operations. The authority is not a public transport operator but, as described in a report from the New Cities Foundation, is a "mobility orchestrator" establishing a mix of contract-based mobility options for the region (Lindsay, 2016). These contracts are subject to public tender and the operators may be commercial entities or publicly-owned companies. European legislation allows for exemptions to the tendering process where the operator is owned by the authority and where such exemptions are not prohibited by national law. In those cases, strict legal obligations on payment, performance and service quality frame the contract.

Because the responsibility for goal-setting and oversight is split from operations and service delivery, this type of model intuitively makes sense for contracting out or procuring services from ride companies. Some of the inherent conflicts that may need to be overcome in the previous two models are not necessarily present and the potential contribution of ride services to an overall vision and objectives for transport can be more objectively assessed and acted upon. This is in theory at least, because in practice, public transport organising authorities in Europe have been particularly loathe to seek out partnerships with ride services and most of the innovation in this field comes from North America. This may stem from the strength and effectiveness of traditional public transport service in European countries as well as from an institutional bias in favour of traditional public transport service delivery models. Yet, even in metropolitan areas with well-functioning public transport networks, operators must often cross-subsidise lower performing routes with revenues derived from core services. Innovation in service delivery in those markets may increase the overall function of the network and improve customers' outcomes.

\section{Current public transport service procurement practices and ride services}

Because many partnerships between public transport agencies and rides services are currently run as trials or on a small scale, they don't necessarily require completely revisiting procurement rules or contracting practices. If these arrangements are to scale up or become an integral part of the transport options overseen by public contracting agencies, adjustments will likely be required to procurement. It is probably too early at this stage to specify what form or forms those contracts and practices should take and the diversity of local conditions would suggest that multiple models may emerge - much as they have for the contracting of public transport services. Further experimentation with procurement rules may even be beneficial as long as risks are identified and contained.

Generally, however, a few elements in the procurement/contracting framework for public transport will need to be adjusted - especially as concerns public service contracts. Public service contracts establish the rights and obligations of both transport authorities contracting services and the operator providing those services. They typically cover a wide range of aspects relevant to the delivery of fixed route public transport services as illustrated in Figure 6. Not all of these areas are necessarily relevant for the oversight of public-private partnerships (where the public transport operator is a public agency or under its effective control and where the ride service operator is a commercial venture) to deliver ride services in conjunction with, or as a replacement for, public transport. In particular, public service contracts typically specify the quantity of services to be provided (in terms of frequency, coverage, vehicles, etc.), may grant exclusivity of fixed routes, set fares, specify how revenue is to be allocated and identify responsibilities for infrastructure investments in return for payments or subsidies for service from the public authority. These 
contract components do not necessarily apply to the provision of ride services as they are typically characterised by routeless networks (with the exception of some microtransit services), fares and revenues are normally the sole responsibility of the ride service (though the difference between the public-facing price and the full cost to the ride service may be part of the contract since this determines the level of public subsidy) and no infrastructure expenditure. Ride service contracts may grant exclusivity to ride service platforms or operators and may specify a geographic scope where the contract and its provisions are enabled.

How contracts and procurement rules specify quality objectives for ride services will likely diverge from traditional bus and rail-based public transport. The latter typically look at specifying operational aspects of service provision: on-time performance, availability of service, location of stops and even detailed schedule-based frequency. These are adapted to the type of services route-based bus and rail services provide but make little sense for platform-based ride services. Coverage of services, average wait times (and their distribution) for both regular services and for accessible services, for example, all focus more on the outcomes that ride services can contribute to and may be more relevant for contracting with the providers of ride services.

An additional element to consider is the allocation of risk in contracting arrangements. Currently, most of the pilots looking at the delivery of ride services allocate risk to the public authority contracting the service. Authorities accept this since they realise substantial cost savings with these arrangements as compared to their prior arrangements. This may need to evolve.

Figure 6. Public service contract components for public transport services and ride services (indicative)

Bus or rail-based public transport

\begin{tabular}{|c|}
\hline \begin{tabular}{|} 
Payments for the services from the \\
competent authority
\end{tabular} \\
\hline $\begin{array}{c}\text { Quality of services } \\
\text { Quantity of services }\end{array}$ \\
\hline $\begin{array}{c}\text { Exclusivity of routes } \\
\text { Roles and tasks of } \\
\text { parties }\end{array}$ \\
\hline $\begin{array}{c}\text { Fares and allocation } \\
\text { of revenues }\end{array}$ \\
\hline $\begin{array}{c}\text { Allocation of } \\
\text { infrastructure costs }\end{array}$ \\
\hline Monitoring and \\
control
\end{tabular}

Ride services

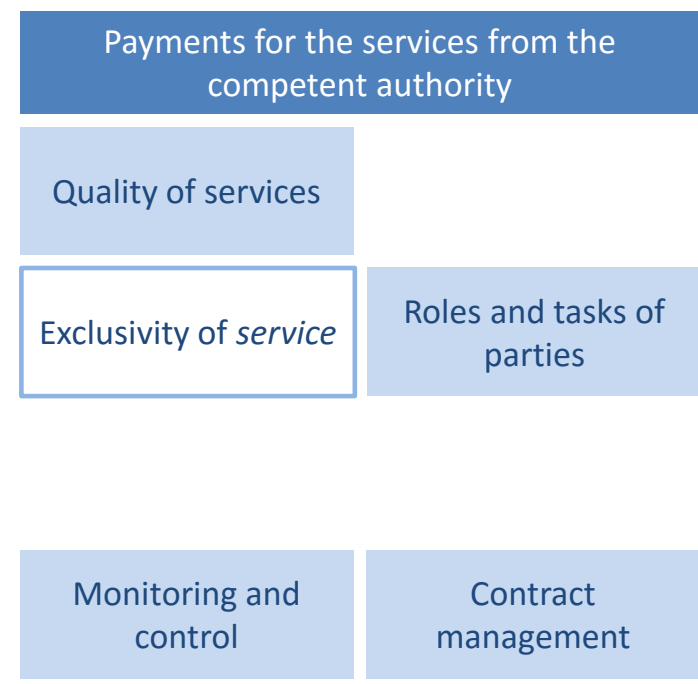

Service area

Source: Based in part on Bruggerman (2014). 


\section{Managing risk linked to service innovation}

Government subsidies or payments for public transport involve taxpayer revenues and because of this, authorities have limited appetite for "risky" investments. If these investments do not provide expected value, the public may feel authorities have squandered taxpayer revenues. This limits the ability for authorities to seek innovative arrangements that may only provide uncertain, or at least, untested value at the outset. Public-private partnerships typically seek to balance risk amongst both parties but are often seen as a way to unload risk to private enterprises in return for which they are compensated through beneficial revenue allocation arrangements. The treatment of risk, both on the cost and on the revenue side is important to consider when looking at the future potential for linking ride services to public transport. In most (temporary) initiatives reviewed here, much of the risk is borne by the contracting public agency or authority.

Risk on the cost side is relatively contained for ride service operators and the platforms they operate, and the remittances they provide drivers are largely covered by general revenues they derive from their commercial services. While there may be some debate on just how profitable different ride service models are, the services they provide in conjunction with public transport options remains a minuscule part of their overall costs. In some cases operators do invest in dedicated services and facilities as Lyft has done in order to provide or pay for call centres. These costs are covered by the ride services. Risk on the cost side for public agencies is also contained since most of the services to-date are time bound pilots with fixed budgets for subsidy payments - once the money runs out, so too does the service unless additional funds are allocated through the budget process. And the pilots typically allow public agencies and operators to enact sometimes substantial cost savings.

Revenue risk is also relatively well contained, since costs are generally contained and marginal revenues cover additional services generated through the pilot programmes. Revenue estimates also oftentimes correctly assume a rise in ridership linked to the greater convenience and contained costs of services offered - especially in comparison to the pre-existing public transport-alone offer.

While risks are contained by design in the case of the pilots described previously, this may not hold true as services scale up and are extended to a broader field of application. In this case, alternative risk mitigation structures may be necessary on the public side. Innovation management is not limited to efforts seeking to reconfigure the provision of mobility services; it is something public agencies are facing across a broad spectrum of fields including broadband access, water services and housing, for instance. In these instances, it may be worthwhile to think about alternative structures that enable sustainable risk-taking in public governance.

One possible approach is to mimic the portfolio approach adopted by many venture capital firms. These firms invest in a broad range of potential new businesses with the expectation that many will fail sometimes quickly; lessons will be learnt and incorporated into new business models and eventually, a sufficient number of ideas take hold and generate adequate returns to sustain and grow the overall portfolio value.

A slightly analogous "innovation finance agency" or "urban mobility lab" could help bring this type of approach to public expenditures in the field of urban mobility innovation. Under this framework, the independent agency might pool public and private monies with an eye to investing in a wide range of innovative services with the expectation that many will fail leading to higher and higher skill and that this, in return, will ensure that some projects succeed, maximise overall return on taxpayer investments and lead to innovative new offers. This approach likely falls outside of the comfort level of many public agencies but some are starting to investigate governance models to help generate innovative services. For example, Metro, Los Angeles' public transport operator, has put in place a programme to receive, evaluate and act upon (if needed) completely unsolicited innovative ideas from the public and from the private sector. 


\section{Box 4. US Federal Transit Agency (FTA) Mobility on Demand Sandbox programme}

The FTA Mobility on Demand (MOD) Sandbox is a federal funding programme aiming to investigate how public transport agencies can develop synergies with, and best manage the disruption caused by, emerging innovative mobility services. The programme helps feed the FTA's research on how new service options in combination with available technologies allow for greater individual mobility. Goals include:

- Improve transportation efficiency by promoting agile, responsive, accessible and seamless multimodal service inclusive of transit through enabling technologies and innovative partnerships.

- Increase transportation effectiveness by ensuring that transit is fully integrated and a vital element of a regional transport network that provides consistent, reliable and accessible service to every traveller.

- $\quad$ Enhance the customer experience by providing each individual equitable, accessible, traveller-centric service leveraging public transportation's long-standing capability and traditional role in this respect.

FTA developed the MOD initiative to envision a multimodal, integrated, automated, accessible and connected transportation system in which personalised mobility is a key feature. FTA's MOD Sandbox programme provides a venue through which integrated MOD concepts and solutions - supported through local partnerships - are demonstrated in real-world settings. The MOD Sandbox also provides FTA the opportunity to measure project impacts and assess how existing FTA policies and regulations may support or impede these new service transportation models through evaluation of all project efforts. The objectives of the programme are to:

- $\quad$ Enhance transit industry preparedness for MOD.

- $\quad$ Assist the transit industry to develop the ability to integrate MOD practices with existing transit service.

- Validate the technical and institutional feasibility of innovative MOD business models and document MOD best practices that may emerge from the demonstrations.

- $\quad$ Measure the impacts of MOD on travellers and transportation systems.

- Examine relevant public sector and federal requirements, regulations and policies that may support or impede transit sector adoption of MOD.

Eligible activities include all those leading to the demonstration of the innovative MOD and transit integration concept, such as planning and developing business models, obtaining equipment and service, acquiring/developing software and hardware interfaces to implement the project, and operating the demonstration. Eligible recipients are providers of public transportation, including public transit agencies, state/local government DOTs, and federally recognised Indian tribes. Each recipient must identify one or more strategic project partner(s) with a substantial interest and involvement in the project. These partners may include private for-profit and not-for-profit organizations, including shared use mobility providers, and technology system suppliers; operators of transportation services, such as employee shuttle services, airport connector services, university transportation systems, or parking and tolling authorities; State or local government entities; and other organisations that may contribute to the success of the project team including consultants, research consortia or not-for-profit industry organisations, and institutions of higher education.

Source: Adapted from FTA (2016).

Another approach to manage more "risky" initiatives is to use dedicated funds and programmes to incentivise innovative projects. The United States Department of Transport has used this approach in its "Smart City" Grant programme and its Federal Transit Agency uses a similar approach in its Mobility on Demand (MOD) Sandbox programme (see Box 4). This program provides up to $80 \%$ matching federal funds (up to the programme budget of USD 8 million) for innovative new integrated mobility-on-demand concepts and solutions. The goal of the programme is to investigate how public transport agencies can develop synergies with, and best manage the disruption caused by, emerging innovative mobility services.

A final risk category to consider is that posed by the "lock-in" of a particular service provider through public agency contracts. Single-provider contracts may make sense but these raise risks of monopolistic behaviour and may prevent more innovative services or providers from entering markets. These risks can be mitigated in a number of ways, for example by shortening the contract period, putting in place 
performance-based contracting with bonuses and penalties for meeting/surpassing or falling short of objectives or splitting the market. Another approach to consider, especially when public authorities provide payments or subsidies for services is to put in place user-side subsidies which allow the private sector to innovate and seek out users who then allocate public funds.

\section{Leveraging government assets to guide convergence}

Public authorities control a substantial amount of infrastructure that can be used or re-configured to help guide the convergence of ride services and public transport. Preferred access to managed lanes, priority given to commercial ride sharing vehicles in publicly owned parking facilities and reconfiguring public street space for pick-up and drop-off zones are all areas where public action can help leverage ownership of infrastructure to support a greater diversity of mobility options.

One issue to consider is that many local authorities derive revenue from infrastructure, especially from parking. A move towards greater reliance on ride services and public transport will likely reduce parking revenues, or at least shift where these are generated. This is in itself not a problem if the costs borne by the public sector also decrease obviating the need for that revenue. But if cost recovery is still required on the part of public authority, it is unlikely that revenue derived from storing inactive vehicles will suffice if a rising share of vehicles provide ride services and therefore only stop briefly at the curb.

In this context, new revenue models may be needed - such as a "kerb-kiss" fee levied for pick-up or drop-off at the kerb applicable to all vehicles (ride services, public transport, goods delivery, etc.) but this would suppose a technological platform able to track and correctly charge these fees in a trustworthy and transparent manner. This may be easier to do at some point in the future, especially with a greater penetration of potentially fully-automated vehicles, but it is worth starting to investigate these models already today.

Another aspect to consider from the public transport operator side is that parking connected to certain stations may also be a constrained resource. In these cases, operators may need to invest significant resources to increase parking capacity for stations servicing extended and low-density catchment areas. As some of the cases outlined in Chapter 3 indicate, partnering with ride services to provide better car-based connectivity to these stations may be in the operator's best interest as this solution can help increase ridership on core services while obviating the need to invest in expensive parking capacity.

\section{Monitoring outcomes}

As noted earlier, there is insufficient reliable evidence on the impacts of joining ride services and public transport, or of using the former to replace the latter. This is precisely why there are so many pilots - they serve as learning exercises both in the organisational aspects of such programmes but also on their impacts. Monitoring outcomes is key at this early stage. However, the metrics used to monitor outcomes should not be limited to those traditionally used by public transport operators in reference to traditional service models. These types of metrics may include on-time performance, average headways, and other operational aspects of public transport production. These are important but they do not capture how the public views the services being offered. Other metrics relating to wait times (average and distribution), frequency, the "feel" of the trip experience (e.g. Los Angeles is tracking transport "happiness"), overall convenience, etc., may be as, or more relevant. These are important metrics that allow agencies and authorities to understand how well users view the mobility offer on hand and whether or not it is compelling enough to effectively compete with car transport.

Another aspect to keep in mind is that even the "production" indices related to ride services are likely to be quite different from those used for public transport. This, in conjunction with the great amount of data 
produced by app-based ride service platforms, has led to calls for ride services - especially (but not only) those engaged in pilots with public transport services - to provide a large amount of data. This typically has occurred in an uncoordinated manner across different cities and countries but there are increasing calls for some form of standardised data-sharing from ride service companies to cities. Certain cities, like New York and London, have compelled ride services to share data in return for operational licensing, while yet others have been unsuccessful with the same companies - possibly because of a poorly structured or overly broad data requests. ITF (2016b) notes how public interest data sharing must balance private security, commercial secrets, valid public insight into the impact of operations and technical capacity on the part of public agencies. It also points out how data sharing - as currently construed - is not the only way, nor even necessarily the best way, to extract useable and trustable insight from ride service data. Nonetheless, the calls for data sharing continue, prompting at least two interesting responses.

In the first instance, Uber has offered to share anonymised trip data with cities through its Movement data platform announced in January 2017. This platform provides city officials and regulators with data on trips in areas where sufficient density allows adequate anonymisation. Information on individual trips is not provided. Movement will give insight into traffic flow speeds and locations where trip density is elevated. It will also provide insights into the manner in which events and other disruptions impact street traffic.

Table 2. NACTO-suggested ride service data sharing elements

\begin{tabular}{|c|c|c|}
\hline \multirow{8}{*}{$\begin{array}{l}\text { 1. Better data for transportation } \\
\text { planning }\end{array}$} & Speed & \multirow[t]{3}{*}{ Corridor } \\
\hline & Volume & \\
\hline & Travel time & \\
\hline & Pick-up location and time & \multirow[t]{2}{*}{ Block face } \\
\hline & Drop-off location and time & \\
\hline & Vehicle occupancy & Corridor \\
\hline & Non-revenue vehicle miles traveled & Log: Miles/month \\
\hline & Vehicle dwell time & Log: Hours/month \\
\hline \multirow[t]{4}{*}{ 2. Equity in mobility options } & $\begin{array}{l}\text { Number, date, and time of } \\
\text { unfulfilled rides }\end{array}$ & \multirow[t]{3}{*}{ Log: Number/quarter } \\
\hline & $\begin{array}{l}\text { Number, date, and time of declined } \\
\text { rides }\end{array}$ & \\
\hline & $\begin{array}{l}\text { Number, date, and time of cancelled } \\
\text { rides }\end{array}$ & \\
\hline & Vehicle availability by type & GPS location data \\
\hline \multirow[t]{5}{*}{ 3. New tools for safety } & Collision occurrence & \multirow[t]{4}{*}{ GPS location data } \\
\hline & Collision severity & \\
\hline & Rapid acceleration & \\
\hline & Rapid deceleration & \\
\hline & $\begin{array}{l}\text { Autonomous vehicle operation } \\
\text { disengagement }\end{array}$ & $\begin{array}{l}\text { Time, location, } \\
\text { and protocol }\end{array}$ \\
\hline
\end{tabular}

Source: NACTO (2017). 
Also in January 2017, the US National Association of City Transportation Officials (NACTO) released its City Data Sharing Principles. These principles cover a much broader set of data than released by Uber through its Movement platform and, for instance, while it may be analogous to some of the data that taxis may have to provide in New York City, it represents a broad expansion of data requests in relation to ride services. This, NACTO states, is necessary in order to enable cities to better carry out data-driven planning and policy decisions, and to help them redesign streets to meet modern needs. Ride services view this expansive data request as over-reaching what might constitute reasonable data sharing on their part. Especially as concerns the potential for the release of privacy-eroding or commercially sensitive data. Furthermore, it isn't clear if all ride service providers even collect some of the data elements specified in the NACTO list, especially as concerns accelerometer data. Very likely that data in particular, will be increasingly generated and stored by vehicles themselves and data discovery will involve automobile manufacturers rather than ride service companies.

Irrespective of the specification for data elements to be shared by ride service companies, there is the issue of fairness in data discovery requirements. The vast majority of traffic entails privately owned vehicles and there are no requirements on these to provide the type of data outlined in the NACTO guidelines. That is partly because there is no defined regulatory mandate to do so. People acquire a right to drive based on passing a minimum skills test and are not restricted in where they may drive except as determined by the rules governing road use. This may change as higher levels of automation come about and there is a need to understand how algorithms operate in traffic - especially as concerns safety outcomes. Public transport and taxi services do operate in a licensed environment and it makes sense that, in return for operations, they too provide the same type of data as being sought from ride services in many cities. This may be an area where further cross-modal harmonisation is required in gathering data for public or commercial services operated on public roads. 


\section{Ensuring equitable access for an ageing population}

One of the recurrent questions in discussions regarding the convergence of innovative mobility services and public transport relates to the broader equity impacts of this convergence as they relate to equitable access. Equity issues extend to many potential groups, including low-income groups, minorities, part-time workers, people with physical and cognitive impairments and the elderly. The Institute for Transport and Development Policy has issued useful guidance in addressing how innovative mobility services can also provide opportunities for low-income households (Kodransky and Lewenstein, 2014). This chapter focuses on what it would take to make innovative mobility services accessible and acceptable to, and useable by, older people and people with physical, sensory or cognitive impairments.

This is an important question and one that will become even more relevant over time. This is due to a close correlation between age and disability; as populations age, disability becomes more prevalent. Virtually every country in the world is experiencing growth in the number of older people in their population. Between 2015 and 2030, the number of people in the world aged 60 years or over is projected to grow by $56 \%$ from 901 million to 1.4 billion, and by 2050 , the global population of older people is projected to more than double its size in 2015, reaching nearly 2.1 billion.

Global ageing has a major influence on disability trends. The relationship is straightforward: there is higher risk of disability at older ages. Informal estimates suggest that some two-thirds of people with disabilities are over retirement age and that one-third of older people have some kind of disability. The prevalence and severity of disability increases with older old age (currently 80 years plus).

Data on disability reveals that across the age spectrum mobility impairments are the most common problem, with difficulty lifting and carrying, poor manual dexterity and problems with communication and memory loss also significant factors. Many older people are affected by a range of impairments including some loss of visual acuity, some loss of hearing, short term memory loss and difficulty gripping, climbing (steps) and balancing. There is also a clear link between a loss of mobility and a decline in physical and mental health and wellbeing. An OECD report noted that "even though disability prevalence rates have declined to some extent in recent years in some countries, the ageing of the population and the greater longevity of individuals can be expected to lead to increasing numbers of people at older ages with a severe disability" (Lafortune and Balestat, 2007).

In terms of providing adequately equipped vehicles, it is important to note that only a small proportion of people with disabilities are wheelchair users. In addition to those with mobility or sensory impairments, many have "hidden" conditions including cognitive and mental health issues. Dementia in all its many forms affects a growing number of people. UK figures indicate that dementia and related neurological conditions affect around $10 \%$ of people aged over 65 and around $50 \%$ of those aged over 80 .

\section{Enabling older people and people with disabilities to travel}

There are a number of key factors to be considered before designing or committing to any transport service or system:

- Low levels of Internet and smartphone access and usage among older people and those with low income (which includes many people with disabilities) (see section below).

- Discomfort/lack of confidence with using on-line systems even if people have access.

- Strong preference for human contact as means of booking trip/seeking advice during trip. In this context services provided in future by driverless vehicles could present particular challenges to the confidence of older people. 
- Reluctance to use automated answering systems/push button options for correct department, etc., which many older and disabled people lack confidence to understand or physical ability to use.

- Concerns about giving out personal/bank information/data.

- Concerns for personal safety (exacerbated by being alone in a vehicle with an unknown driver).

- Need for social interaction that comes with mainstream bus/train travel.

- Physical accessibility of vehicles (more difficult in smaller vehicles). Features need to include: wheelchair access (not necessarily all vehicles but see next point), low level entry, grab handles, swivel seats, colour contrast, arm rests.

- Availability of vehicles for spontaneous travel: Many cities in Europe and North America now have mainstream public transport that is accessible to many people with disabilities, including wheelchair users. If that is replaced by on-demand mobility services, the same level of accessibility/availability will be needed.

Another key consideration relating to the delivery of app-based ride services is whether or not current and successive older populations are capable of using these services - are they technologically savvy? This is an important consideration since increasingly, internet and/or smartphone access is needed to organise spontaneous travel and to get the best price deals on trips. For many older people this represents a major barrier:

- $44 \%$ of Americans aged 65 and above are not on-line.

- Only $27 \%$ of Americans aged over 65 have a smartphone (compared with $85 \%$ of those aged 18-29. Although this might suggest that the next generation of older people will be more comfortable with technology, note the final bullet in this section.

Some of the difficulties for older people using technology include:

- poor manual dexterity affecting ability to use keyboard and touch screen

- vision problems affecting ability to read screens and keyboards

- confusion and short-term memory loss making on-line transactions difficult and stressful

- concern about data security and reluctance to disclose personal information.

These difficulties are likely to persist even as currently technologically savvy generations age. It is likely that as each generation reaches old age, it will face similar difficulties as the pace of technology moves faster than people's ability to stay ahead of it mentally and physically. Given the likely increase in prevalence of digital interfaces - especially in the context of Mobility as a Service (MaaS) - designing services that are accessible for as wide a population as possible will become a core concern. This is already the case for Finland, a pioneer in MaaS policy and deployment (see Box 5).

\section{Current accessibility trends in transport}

Against the background of the discussion on mobility services, it is important to understand both the historical context and the current situation on transport accessibility. Over the past 30 years, in North America, Europe and elsewhere there have been developments, initiated by the civil rights movement and increasingly enshrined in law, to require all public transport to be designed and operated by vehicles and systems accessible to people who use wheelchairs, have walking difficulty, impaired sight or hearing, etc. In many towns and cities $100 \%$ of public transport is now accessible. These developments have opened up 
opportunities for people with disabilities to live independent lives, to enjoy spontaneous travel and to access employment, education and social activities freely.

\section{Box 5. Mobility as a Service and accessibility: Experience and guidance from Finland}

Finland is an early leader in terms of integrating the concept of Mobility as a Service (MaaS) into regulatory frameworks, data structures and systems, operational rules and commercial deployment. Government policy aims to ensure that the deployment of these services does not exclude people requiring assistance to travel or those with various physical and cognitive disabilities.

In Finland more than $19 \%$ of the population is considered disabled and 1.2 million people are over 65 years old. Any system inaccessible to these people prevents their contribution and equitable participation in society. Digitalisation of information acquisition about, and the purchase of, transport services has led to great efficiencies but simultaneously, has eroded the ability for the non-digitally savvy or those who cannot use non-accessible digital interfaces to travel easily. This trend in digitalisation has been accompanied by a reduction of personal customer service in vehicles, terminals, service centres and call centres. This increases the risk of marginalisation for those that those who cannot use mobile devices due to age, disability, language skills, or other reasons.

There is a strong push in Finland to ensure that MaaS deployment also includes accessibility considerations. This takes several forms at present:

- $\quad$ There is a need for structured and standardised data to be communicated across the range of MaaS actors regarding travel route accessibility and vehicular accessibility and capacity. This data should be an integral part of the data package provided by transport operators to MaaS operators and eventually to customers. This data is required by law to be available in machine readable format through open interfaces by 1 January 2018. These essential accessibility data elements via open interfaces are required by the Finnish Transport Code (TC) coming into force in 2018 and covers all transport modes and services. However each transport mode have their mode specific data attributes, so additional work is underway to define "agreed minimums" for the most critical data.

- $\quad$ Data regarding passengers special needs should be delivered in standardised form from MaaS operators to the producers of transport services. The MyData model (https://mydatafi.wordpress.com/) that emphasises the users right to limit or share the use of their personal data, could allow even more detailed health and personal data to be communicated via application programming interfaces. Model interfaces are being developed under a implementation project for the Finnish TC.

- Accessibility should be designed into user interfaces from the outset using existing and accepted standards.

- $\quad$ Additional services, e.g. call centre and alternative sales channels, will be needed for those who cannot use digital user interfaces. Responsibilities in organising these additional services will need to be allocated between public and commercial actors according to common rules. The new Finnish TC gives public entities more flexibility to purchase or cover additional expenses to organise rural area or night duty coverage for people with special needs.

Source: Adapted from Somerpalo et al. (2017).

Door-to-door or paratransit services, common in North America and many parts of Europe, which were the starting point for accessibility for older and disabled people, are increasingly seen as a complement to rather than a substitute for accessible public transport. In some cities (for example Barcelona and London), the transport operator encourages people to use public transport rather than "special" services by providing a mentor or companion to travel with them until they are comfortable with the route and the process.

For those older people who have never been public transport users, the prospect of giving up driving is often very frightening and as a consequence, many stay behind the wheel longer than they should. Many are deterred by the complexity of accessing and understanding bus or rail timetables or purchasing tickets. At the same time, they may feel intimidated by ride services that combine technological elements that they may poorly master and the need to provide banking details in advance. 


\section{Suggested prerequisites for inclusive mobility services}

Taking on board the points set out above, if mobility services complement or replace accessible mainstream public transport, they would need to provide at least the same degree of spontaneity and flexibility to travel when the individual wants or needs. In cities where frequent accessible buses and on-street hail taxis are available, this would mean ensuring that ride services licensed by public authorities provide services as accessible as those they complement or replace and that drivers are sufficiently trained. This may mean a substantial number of vehicles deployed would meet international accessibility standards. On-going monitoring of these outcomes is necessary.

However, in places without this tradition of high levels of accessibility, or where on-street hailing is less frequent and bus service headways poorer, a proportion of accessible vehicles could probably meet demand, although defining the optimum number would depend on the efficiency of booking and vehicle location systems. This seems to be the case for many of the US-based pilot programmes. As part of this provision, real-time mapping system would need to be able to locate and book the nearest accessible vehicle. In all circumstances and situations, an adequate pool of accessible vehicles would need to be available at all times so that people with disabilities did not have to wait (much) longer than other people to make their trip. There is some experimentation underway (e.g. Uber in New York City) on mixing short-term leases for accessible vehicles, a flat incentive payment for drivers undertaking those trips and reduced commissions by the ride service platform. In contexts where accessibility requirements impose that all public transport vehicles are accessible and public transport frequencies are high, a move to longer wait times for accessible ride service vehicles will represent a retrograde step.

Drivers providing accessible services would need to have specialist training in understanding and meeting the needs of older people and people with disabilities. This would include both disability awareness training and job specific practical training in areas such as guiding a blind person, assisting a wheelchair user, understanding and supporting a person with dementia.

Furthermore, a system would need to be set up that incentivised companies/drivers to purchase more expensive accessible vehicles and that compensated them for making fewer trips because of the time taken to assist a passenger with a disability. These are the principles that guided the development of MBTA's RIDE pilot.

Close monitoring and a contractual framework would need to be in place to ensure that drivers/companies were not avoiding the calls from people with disabilities (there is some evidence of this from the introduction of accessible taxis is the UK and elsewhere).

For younger people with physical or sensory disabilities (at least in the developed world), internet access and smartphone use is generally not a problem with new technology compensating for lack of manual dexterity or vision, etc. Provided that vehicles were suitable and drivers were trained, they would mostly adapt without difficulty. For those with learning disabilities or mental health issues, the challenges would include understanding how to use the system and being able to trust the driver (police checks as well as training would be necessary for all drivers dealing with vulnerable passengers). Non hi-tech systems such as those suggested below for older people might also be helpful to those with learning disabilities.

For older people without access to the internet or without the skills to make bookings and other transactions, alternatives could include:

- a phone line, staffed by people (Lyft has put in place this service in some of its paratransit pilots in the United States)

- access points in local shops and cafés where people would be available to help with the transaction 
- a simple means of data protection that would give older people the confidence that their personal finances were not being compromised

- enabling people to travel with a companion at no charge or reduced charge to give people the confidence to make the journey (particularly important for those with dementia and a common policy among mainstream local transport providers).

\section{Can mobility services meet everyone's needs?}

The section above sets out some of the basic parameters for accessibility, acceptability and usability by older people and people with disabilities. Some other issues also need to be addressed, such as consistency of service, equality and social issues.

For many older people, particularly those living alone, using public transport may be the only opportunity for social interaction and is an important part of retaining their ability to live and to function independently. Social interaction is a major factor in preventing both physical and mental decline (which represent a huge economic cost to society, as well as social and personal cost to the individual). Travelling as the only passenger is a vehicle will not provide the same stimulation and may cause anxiety, which leads to a preference for inclusive services, covering all users including those with access needs. Also, the ability to travel with a companion (at no extra costs) would help with this concern both for older people and for those with mental health issues or learning disabilities.

One of the key achievements of the past 30 years (in Europe and North America among others) has been to achieve harmonised and consistent rules on what accessible vehicles should look like so that people with disabilities can travel with confidence knowing that they will be able to complete all stages of their journey. It will be important for the criteria for vehicle accessibility to be clearly defined and non-negotiable otherwise there is a risk of sending an "accessible "vehicle that cannot accommodate, for example, someone travelling in a large wheelchair or with a mobility scooter.

To avoid a major backlash from the disability community that 30 years of campaigning for civil rights has been thrown away, it is vital that mobility services are promoted and introduced as a new way of travel for the population as a whole and one that is as universally accessible as public transport has increasingly become. There is otherwise a risk that it will look as if there is a regression back to the days of separate specialised transport.

\section{What about the future? Testing equitable accessibility of shared mobility services}

Going forward, it seems clear that urban mobility markets will undergo significant changes as ride services and other, innovative, mobility services are developed in conjunction with, or as competition to, existing transport options including personal car use, taxis and public transport. At the same time, as mentioned in the opening of this report, there is considerable uncertainty regarding which business model (or models) will prevail and what role public authorities will play in facilitating, guiding or blocking new initiatives from the private sector. This uncertainty extends to the ability for new business models to address the mobility and accessibility needs of the entire population. In order to help reduce some of this uncertainty, ITF has investigated the extent to which shared mobility systems as modelled in previous work (see ITF 2015; 2016c) could handle the needs of a population requiring special assistance or accessible vehicles to travel. It finds that under certain configurations, deploying a fleet of fully accessible vehicles is an attractive and cost-effective solution (see Box 6). While the shared mobility services modelled in the work represent just one potential mobility market in the future, the work suggests that pro-consumer innovation can, when 
carefully and purposefully designed, also result in better outcomes for all urban travellers - including those with physical or cognitive disabilities.

\section{Box 6. Inclusive mobility services based on shared rides}

The ITF has undertaken extensive modelling of optimised shared-use mobility services in urban areas (see ITF, $2015 ;$ 2016d) as a way of re-thinking the nature of urban public-transport-like services. This work has shown how the flexibility and convenience of demand-responsive shared mobility solutions can lead to better mobility, congestion, environmental and spatial accessibility outcomes.

But what about the potential contribution of such systems to improved access for older people and those with reduced mobility, including individuals with physical, sensory, or cognitive disabilities or travellers carrying heavy bags or accompanying young children? ITF proposes a framework to value the social and economic benefits of improved access, including time savings, greater convenience, more employment opportunities and savings across the social care and health sectors (ITF, 2016d).

A new ITF report (ITF, 2017) assumes that $10 \%$ of all trips in an urban simulation will be generated by people requiring accessible vehicles, and that these trips are carried out only by on-demand, door-to-door, Shared Taxi services. Other trips are handled by demand-responsive mini-bus services, high-capacity public transport, walking as well as by Shared Taxis. Accessible service trips are carried out by vehicles fitted with a ramp (or a lift), a wider door (on the side or on the back) and a safe place to anchor a wheelchair along the lines required by the US ADA (Americans with Disabilities Act)(United States Access Board, 1991) or other applicable national standards. Not all "accessible" trips require wheelchair access vehicles but for the purposes of the exercise, the ITF only modelled one accessible vehicle class.

Wheelchair accessible vehicles have a higher capital cost (the report assumes $40 \%$ more) and have higher fuel costs ( $10 \%$ more in the simulation) due to the higher weight. In addition, the longer boarding and alighting times for people with special mobility needs can imply somewhat lower service productivity. For these two reasons, delivering a disability-accessible service costs a bit more in the modelling exercise than a service that has no accessible vehicles.

In cities that provide on-call paratransit services travellers requiring accessible vehicles often have 24-hour advance reservation requirements. In this case, the model specification was set such that people requiring accessible vehicles would face the same (rather low) maximum acceptable waiting times for all other travellers. The most optimal approach to ensure this was to model a Shared Taxi fleet that was $100 \%$ accessible - as is the case in certain cities around the world.

Taking all of these considerations into account, the report finds that, when modelling a scenario considering that $10 \%$ of the travelling population has special mobility needs and including $100 \%$ accessible Shared Taxis, the breakeven price per passenger.kilometre (including overheads and profits) was only a bit higher than in the scenario with no accessible Shared Taxis, and still at $60 \%$ of the current equivalent price for public transport. International evidence also points to the potential of accessible transport systems to generate large economic benefits (ITF, 2016d).

The main reasons for the quite small increment in the price per passenger.kilometre in spite of the $40 \%$ higher capital costs and $10 \%$ fuel costs of the adapted vehicles, are the large distances run each day by these shared vehicles and the relatively large part of the costs corresponding to labour.

These results confirm the high value of shared solutions also for this particular segment of the urban mobility market, and thus a promising option offering high levels of personal accessibility in an inclusive and very efficient scheme. 


\section{Bibliography}

Demaio, P. (2017), "Year-end wrap-up". LLC MetroBike. 10 January 2017. http://bikesharing.blogspot.com/2017/01/2016-year-end-wrap-up-will-appear-at.html (accessed 8 February 2017).

Feigan, S. and C. Murphy (2016), "Shared Mobility and the Transformation of Public Transit.".

FTA (2016), Mobility on Demand (MOD) Sandbox Program. https://www.transit.dot.gov/researchinnovation/mobility-demand-mod-sandbox-program.html (accessed 10 May 2017).

FTA (2017), Shared Mobility Frequently Asked Questions. https://www.transit.dot.gov/regulations-andguidance/shared-mobility-frequently-asked-questions (accessed 10 May 2017).

Hensher, D.A. (2017), "Future bus transport contracts under a mobility as a service (MaaS) regime in the digital age: Are they likely to change?" Transportation Research Part A: Policy and Practice, Vol. 98 .

ITF (2017), "Introducing Shared Mobility: How cities can manage the transition to new, more inclusive, transport services." International Transport Forum Policy Papers, OECD Publishing, Paris.

ITF (2016a),"App-Based Ride and Taxi Services: Principles for Regulation". International Transport Forum Policy Papers, No. 22, OECD Publishing, Paris.

DOI: http://dx.doi.org/10.1787/5jlwvz87ngvf-en

ITF (2016b), "Data-driven Transport Policy." International Transport Forum Policy Papers, No. 20, OECD Publishing, Paris.

DOI: http://dx.doi.org/10.1787/5jlwvz8g4vbs-en

ITF (2016c), "Shared Mobility: Innovation for Liveable Cities." International Transport Forum Policy Papers, No. 21, OECD Publishing, Paris.

DOI: http://dx.doi.org/10.1787/5jlwvz8bd4mx-en

ITF (2016d), "The Economic Benefits of Improved Accessibility to Transport Systems." International

Transport Forum Policy Papers, OECD Publishing, Paris. http://www.itf-

oecd.org/sites/default/files/docs/economic-benefits-improved-accessibility_0.pdf

ITF (2015), "Urban Mobility System Upgrade: How shared self-driving cars could change city traffic." International Transport Forum Policy Papers, No. 6, OECD Publishing, Paris.

DOI: http://dx.doi.org/10.1787/5jlwvzdk29g5-en

ITF (2014), Valuing Convenience in Public Transport, OECD Publishing, Paris.

DOI: http://dx.doi.org/10.1787/9789282107683-en

Kaufman et al. (2015), Intelligent Paratransit, Rudin Center for Transportation Policy and Management, New York University, New York City.

Kodransky, M. and G. Lewenstein (2014), Connecting Low-Income People to Opportunity with Shared Mobility. Institute for Transportation and Development Policy, New York.

Lafortune, G. and G. Balestat (2007), "Trends in Severe Disability Among Elderly People: Assessing the Evidence in 12 OECD Countries and the Future Implications", OECD Health Working Papers, No. 26, OECD Publishing, Paris.

DOI: http://dx.doi.org/10.1787/217072070078

Larsen, N.T. (2016), "Adapting the best elements of the Danish approach to combine several types of transportation." Transportation Research Board, International Conference on Demand Responsive Transportation: Paratransit from Dial-a-Ride to Technology Enabled Services. Breckenridge.

Lindsay, G. (2016), "Now Arriving: A connected mobility roadmap for public transport." New Cities Foundation (October).

Marshall, A. (2017), How a Failed Experiment Could Still Be the Future of Public Transit. https://www.wired.com/2017/03/failed-experiment-still-future-public-transit/ (accessed 23 March 2017).

NACTO (2017) NACTO City Data Sharing Principles. https://nacto.org/policy-2016/city-data-sharingprinciples/ (accessed 10 May 2017). 
Schaller, B. (2017), "Unsustainable? The Growth of App-Based Ride Services and Traffic, Travel and the Future of New York City.": Schaller Consulting, Brooklyn (February 27).

Schaller, B. (2016a), "Unfinished Business: A Blueprint for Uber, Lyft and Taxi Regulation." Schaller Consulting, Brooklyn (September 20).

Schaller, B. (2016b), "Living in an App-Enabled World: Implications for transit agency leadership, management and service delivery." Transportation Research Board, International Conference on Demand Responsive Transportation. Breckenridge.

SFMTA (2015), Travel Decisions Survey 2015, San Francisco: San Francisco Municipal Transportation Agency.

Shaheen, S., A. Cohen and I. Zohdy (2016a), Shared Mobility: Current Practices and Guiding Principles. US DEpartment of Transportation: Federal Highway Administration, Washington, DC.

Shaheen, S., A. Cohen, I. Zohdy and B. Kock (2016b), Smartphone Applications to Influence Travel Choices. US Department of Transportation: Federal Highway Administration, Washington, DC..

Shaheen, S., A. Stocker, J. Lazarus and A. Bhattacharyya (2016c). RideKC - Bridj Pilot Evaluation:Impact, Operational, and Institutional Analysis. Transportation Sustainability Research Center (TSRC), UC Berkeley..

Somerpalo, S., T. Tamminen and P. Alinikula (2017),. "Advancing accessibility of digital transport services." Helsinki: Finnish Ministry of Transport and Communications, 24 January.

Stamen Design (2015), The City from the Valley. https://hi.stamen.com/the-city-from-the-valley57e835ee3dc6 (accessed 23 March 2017).

Tsay, S.P., Z. Accuardi, B. Schaller and K. Hovenkotter (2016), Private Mobility, Public Interest: How Public Agencies can work with Emerging Mobility Providers. New York City: Transit Center.

UTTP (2009), Organising Authorities Committee, Organising Authorities Mission Statement, Union Internationale des Transports Publics, Brussels.

\section{Notes}

\footnotetext{
${ }^{1}$ According to Wheels, Route 3, which connected suburban residential areas in West Dublin to BART during peak times, carried approximately five passengers per hour and had a subsidy of over USD 15/passenger trip (http://www.wheelsbus.com/services/wheels-on-demand/).

${ }^{2}$ For more information: https://www.transit.dot.gov/shared-mobility.
} 


\section{E International Transport Forum}

\section{Shaping the Relationship Between Public Transport and Innovative Mobility}

This report investigates the convergence of public transport and innovative mobility solutions, such as ride services, car- and bicycle-sharing, app-enabled on-demand micro-bus services, and platforms that connect app-using travellers and drivers. It examines the role of public authorities in ensuring this convergence supports commercial innovation as well as public policy objectives and identifies principles to guide partnerships between innovative mobility services and public transport operators.

The work for this report was carried out in the context of a project initiated and funded by the International Transport Forum's Corporate Partnership Board (CPB). CPB projects are designed to enrich policy discussion with a business perspective. Led by the ITF, work is carried out in a collaborative fashion in working groups consisting of CPB member companies, external experts and ITF researchers. 